FACTA UNIVERSITATIS

Series:Mechanical Engineering Vol. 19, № 3, Special Issue, 2021, pp. 555 - 578

https://doi.org/10.22190/FUME210521059K

Original scientific paper

\title{
AN EXTENDED SINGLE-VALUED NEUTROSOPHIC AHP AND \\ MULTIMOORA METHOD TO EVALUATE THE OPTIMAL TRAINING AIRCRAFT FOR FLIGHT TRAINING ORGANIZATIONS
}

\section{Çağlar Karamaşa ${ }^{1}$, Darjan Karabasevic ${ }^{2}$, Dragisa Stanujkic ${ }^{3}$, Alireza Rezanezhad Kookhdan ${ }^{4}$, Arunodaya Raj Mishra ${ }^{5}$, Mehmet Ertürk ${ }^{6}$}

${ }^{1}$ Faculty of Business, Department of Business Administration, Anadolu University, Eskişehir, Turkey

${ }^{2}$ Faculty of Applied Management, Economics and Finance,

University Business Academy in Novi Sad, Belgrade, Serbia

${ }^{3}$ Technical Faculty in Bor, University of Belgrade, Serbia

${ }^{4}$ Faculty of Management, Islamic Azad University Arak Branch, Arak, Iran

${ }^{5}$ Department of Mathematics, Govt College Jaitwara, Satna, India

${ }^{6}$ Faculty of Aviation and Aeronautical Sciences, Department of Civil Aviation

Management, Özyeğin University, Istanbul, Turkey

\begin{abstract}
Aircraft's training is crucial for a flight training organization (FTO). Therefore, an important decision that these organizations should wisely consider the choice of aircraft to be bought among many alternatives. The criteria for evaluating the optimal training aircraft for FTOs are collected based on the survey approach. Single valued neutrosophic sets (SVNS) have the degree of truth, indeterminacy, and falsity membership functions and, as a special case, neutrosophic sets (NS) deal with inconsistent environments. In this regard, this study has extended a single-valued neutrosophic analytic hierarchy process $(A H P)$ based on multi-objective optimization on the basis of ratio analysis plus a full multiplicative form (MULTIMOORA) to rank the training aircraft as the alternatives. Moreover, a sensitivity analysis is performed to demonstrate the stability of the developed method. Finally, a comparison between the results of the developed approach and the existing approaches for validating the developed approach is discussed. This analysis shows that the proposed approach is efficient and with the other methods.
\end{abstract}

Key Words: Training Aircraft Selection, Neutrosophic Sets, Flight Training Organization, Civil Aviation, AHP, MULTIMOORA

Received May 21, 2021 / Accepted August 18, 2021

Corresponding author: Çağlar Karamaşa

Anadolu University, Faculty of Business, Department of Business, Administration, Eskişehir, Turkey

E-mail: ckaramasa@ anadolu.edu.tr; ckaramasa@gmail.com 


\section{INTRODUCTION}

Aircraft selection offers complex objectives that do not allow the decision-making approach to use only one variable [1-5]. Among other reasons, a multi-criteria approach becomes necessary when the number of objectives to be met is greater than or equal to two, and they are contradictory [6]. A good first training aircraft is vital for the success of flight training, so the performance of the first training aircraft is an important factor [7]. The selection of aircraft has historically been of great interest and considerable research effort [8]. For various reasons, most of the published reports have made a choice for military pilot training, although the entire military training is directly applicable to civil aviation [9]. In order to solve the aircraft type selection problem, the anticipated demand for the routes considered and operated by the same aircraft types is taken as input data [10]. The critical problem in this assessment is the selection of an aircraft, as this represents the main part of the required investment [11].

Airlines create much more value than other components of the airline industry as a growing service sector and have the lowest return on capital ratio. Airline companies are mostly affected by increased competition in the past decades. Generally, most aircraft are expected to have a service life of 30 years or more, but several uncertainties could affect the viability and applicability of the aircraft during its service life. For example, the price of fuel is always affected by the economic situation. The load factor changes throughout the year. Therefore, these economic uncertainties need to be taken into consideration when deciding to purchase new aircraft for an organization [12].

Aircraft selection can be taken as the most important investment decision for airline companies due to having an effect on the type and quality of services presented to customers [13]. Aircraft selection is a complex system engineering that includes aircraft parameters, engine performance, communication and navigation technology, flight dynamics, meteorology, art design, financial management, and corporate strategic planning [14]. Therefore, all these variables should be taken into consideration when selecting training aircraft. Neutrosophic Sets (NS) having the degree of truth, indeterminacy, and falsity membership functions as totally independent are introduced by Smarandache [15] for explaining decision-makers ambiguity and inconsistent judgments. Studies composed of neutrosophic sets based on multi-criteria decision-making methods have increased and gained importance in the last decades. The idea of the proposed method is to extend the Analytic Hierarchy Process (AHP) based Multi-Objective Optimization on the Basis of Ratio Analysis plus a full multiplicative form (MULTIMOORA) approach via single-valued neutrosophic sets and show the applicability on aircraft selection as a Multiple Criteria Decision Making (MCDM) problem.

Training plane assessment has always been a big issue for flight training academies. Right aircraft selection is very important for both organizations and practitioners. Although the selection of the optimal training aircraft for flight training organizations (FTOs) is a crucial concept, a few previous studies highlighted this issue in the literature. Therefore, a novel approach using AHP-MULTIMOORA is developed with SVNS and applied for aircraft selection problems by considering the decision-makers truth, indeterminacy, and falsity judgments in the real-life environment. Sensitivity analysis and comparison with previous methods are executed to show the strength of the approach. For this purpose, SVNS, as a case of NS is used with an integrated approach. In addition, an aircraft selection problem is handled for showing the approach and presented the 
performance in practical MCDM problems. Sensitivity analysis is executed for the visual presentation of the outcome. Finally, a comparison is made for showing the strengths of the results. The major outcomes of the paper can be summarized as follows:

The rest of this study is organized in the following sections. In the first part information related to flight training organizations and the issue of optimal training aircraft selection is presented. Literature review related to training plane selection in terms of multi-criteria decision-making methods is expressed in the second section. A single-valued neutrosophic AHP and neutrosophic MULTIMOORA are stated under methodology in the third section. The results of the analysis and findings are presented in the fourth section. Finally, conclusions and future suggestions are given in the last section.

\section{LITERATURE REVIEW}

In past decades, several published papers in aircraft selection have used different decision-making approaches related to classical and fuzzy sets. Therefore, a detailed literature review related to the application of conventional and fuzzy decision-making methods in the area of aircraft selection is presented in Table 1.

AHP [30] and MULTIMOORA [31], as MCDM approaches have been widely applied to various realistic problems. The classical AHP and MULTIMOORA methods have been handled for overcoming MCDM problems in various environments. The summary of the available study on AHP and MULTIMOORA approaches is depicted in Table 2.

According to Tables 1 and 2, there is no study examining the decision problem by using AHP based MULTIMOORA method from single-valued neutrosophic sets. That shows the originality and novelty of this method for the application of training aircraft selection. Decision-makers can explain their indeterminate and uncertain judgments more flexibly and efficiently than classical, fuzzy, hesitant, and intuitionistic sets. AHP as a subjective weighting method is selected for prioritizing the importance values of criteria due to considering the inconsistency for decision-makers' judgments and presenting more realistic and practical results for real-world uncertain decision-making problems. MULTIMOORA as a robust alternative ranking method is handled because of making a decision based on the dominance of three approaches.

Fuzzy sets (FSs) doctrine originated by Zadeh [52], has widely been utilized to cope with the uncertainty that occurred in several fields. In recent times, several extensions of FSs such as interval-valued fuzzy sets (IVFSs) [53], intuitionistic fuzzy sets (IFSs) [54], Pythagorean fuzzy sets (PFSs) [55], and q-rung orthopair fuzzy sets (q-ROFSs) [56] have been introduced and implemented in the field of pattern recognition, decision-making, medical diagnosis, etc. [57-59]. However, the notions of FS and its generalizations can only handle incomplete and uncertain information but are unable to tackle the indeterminate and inconsistent information that arises in real-life issues. To handle this concern, Smarandache [15] pioneered the idea of neutrosophic set (NS) for describing incomplete, indeterminate and inconsistent information, which is a branch of philosophy as well as a mathematical tool for studying the origin, nature, and scope of neutralities. NS is characterized by the truthmembership, indeterminacy-membership and falsity- membership functions, which are totally independent and lying in $] 0^{-}, 1^{+}[$. For example, assume that 10 voters are taking part in a voting process. Suppose four votes are "yes", two votes are "no" and three are undecided. In neutrosophic sense, it can be expressed as $(0.4,0.3,0.2)$, which is beyond the 
scope of IFS. According to Smarandache [60], it is the generalized concept of FS, IFS, IVIFS, PFS, q-ROFS, PiFS, Ternary fuzzy set (TFS), Spherical fuzzy set (SFS) and nHyper Spherical fuzzy set (n-HSFS). As the NS is a more suitable tool to capture the incomplete, indeterminate and inconsistent information, it has been widely utilized for several purposes [61-63].

Table 1 Outline of the relevant research studies on aircraft selection

\begin{tabular}{|c|c|c|}
\hline Author(s) & Benchmark & Environment \\
\hline See and Lewis [16] & Multiattribute Decision-Making methods & Classical sets \\
\hline Wang and Chang [7] & $\begin{array}{l}\text { The Technique for Order of Preference by Similarity to } \\
\text { Ideal Solution (TOPSIS) method }\end{array}$ & Fuzzy Sets \\
\hline Yeh and Chang [17] & $\begin{array}{l}\text { A new method for modeling group subjective evaluation } \\
\text { with absolute judgments }\end{array}$ & Fuzzy Sets \\
\hline Özdemir et al. [18] & Analytic Network Process (ANP) & Classical sets \\
\hline Dozic and Kalic [8] & AHP and sensitivity analysis & Classical Sets \\
\hline Gomes et al. [11] & $\begin{array}{l}\text { Novel Approach to Imprecise Assessment and Decision } \\
\text { Environments (NAIADE) method }\end{array}$ & Fuzzy Sets \\
\hline Bruno et al. [19] & AHP & Fuzzy Sets \\
\hline Kannan et al. [20] & Novel framework using TOPSIS & Fuzzy Sets \\
\hline Dozic and Kalic [10] & AHP and Even Swaps Method (ESM) & Classical set \\
\hline Lozano et al. [21] & AHP and TOPSIS & Fuzzy Sets \\
\hline Göleç et al. [22] & $\begin{array}{l}\text { AHP, Simple Additive Weighting (SAW), ELimination } \\
\text { and Choice Expressing REality (ELECTRE) and TOPSIS }\end{array}$ & Classical sets \\
\hline Ozdemir and Basligil [23] & ANP and Generalized Choquet Integral & Fuzzy sets \\
\hline $\begin{array}{l}\text { Yurdusevimli and } \\
\text { Ozger[24] }\end{array}$ & AHP and TOPSIS & Classical sets \\
\hline Dozic et al. [1] & $\begin{array}{l}\text { Fuzzy AHP and Logarithmic Fuzzy Preference } \\
\text { Programming (LFPP) }\end{array}$ & Fuzzy Sets \\
\hline Kiracı and Bakir[25] & $\begin{array}{l}\text { AHP, Complex Proportional Assessment (COPRAS) and } \\
\text { Multi-Objective Optimization Method by Ratio Analysis } \\
\text { (MOORA) }\end{array}$ & Classical sets \\
\hline $\operatorname{Ilg} 1 \mathrm{n}[13]$ & Linear Physical Programming & Classical sets \\
\hline Maywald et al. [4] & Multi-step heuristic algorithm & Classical sets \\
\hline Durmaz and Gencer[26] & SWARA and SMAA-2 & Classical sets \\
\hline Kirac1 and Akan [27] & AHP and TOPSIS & $\begin{array}{l}\text { Interval type-2 fuzzy } \\
\text { sets }\end{array}$ \\
\hline $\begin{array}{l}\text { Sanchez-Lozano and } \\
\text { Rodriguez [6] }\end{array}$ & AHP and Reference Ideal Method & Fuzzy sets \\
\hline Ahmed et al. [28] & AHP and efficacy method & Fuzzy sets \\
\hline Hoan and Ha [29] & ARAS and FUCOM & Classical sets \\
\hline
\end{tabular}

However, without a specific description, it is difficult to implement the NSs to scientific and engineering problems as the truth-membership, indeterminacy-membership and falsitymembership functions lie in $] 0^{-}, 1^{+}[$.To overcome this limitation, Wang et al. [64] originated the doctrine of single-valued neutrosophic sets (SVNSs), whose values belong to [0, 1]. SVNSs can be considered as a subclass of NSs. It provides us an additional possibility to represent imprecise, incomplete, uncertain and inconsistent information, which exists in realworld. The notion of SVNS has been proven as one of the flexible ways for solving group decision-making (GDM) problems. For instance, Liu et al. [63] suggested a novel GDM model based on DEMATEL approach with SVNSs for evaluating the transport service providers. Pamučar and Božanić [65] evaluated the location for the logistics center by employing single-valued neutrosophic MABAC model. Rani and Mishra [66] designed an integrated decision-making framework based on SWARA and VIKOR approaches with 
SVNSs and applied to deal with eco-industrial thermal power plants. Apart from these studies, several aggregation operators [67], information measures [68-69], and decision-making methods [70] have been developed in the context of SVNSs. However, there is no study in the literature regarding the evaluation of the optimal training aircraft for flight training organizations under SVNSs environment.

Table 2 Outline of several of the relevant research studies on AHP and MULTIMOORA methods

\begin{tabular}{|c|c|c|}
\hline Author(s) & Benchmark & Application(s) \\
\hline $\begin{array}{l}\text { Brauers and Zavadskas } \\
\text { [32] }\end{array}$ & MULTIMOORA method & Decide upon a bank loan to buy property \\
\hline Balezentis and Zeng [33] & $\begin{array}{l}\text { MULTIMOORA extended with } \\
\text { type- } 2 \text { fuzzy sets }\end{array}$ & Personnel selection \\
\hline Aksoy et al. [34] & $\begin{array}{l}\text { AHP based MULTIMOORA and } \\
\text { COPRAS }\end{array}$ & $\begin{array}{l}\text { Evaluating the performance of Turkish Coal } \\
\text { Enterprises }\end{array}$ \\
\hline Hafezalkotob et al. [35] & Interval weighted MULTIMOORA & Materials selection of power gears \\
\hline Karabasevic et al. [36] & $\begin{array}{l}\text { MULTIMOORA and Step-wise } \\
\text { Weight Assessment Ratio Analysis } \\
\text { (SWARA) }\end{array}$ & $\begin{array}{l}\text { Selection of a candidate for the position of the } \\
\text { mining engineer for underground mining }\end{array}$ \\
\hline Zavadskas et al. [37] & $\begin{array}{l}\text { SWARA and MULTIMOORA with } \\
\text { single-valued neutrosophic set }\end{array}$ & $\begin{array}{l}\text { Selection of single-family house elements and } \\
\text { materials }\end{array}$ \\
\hline $\begin{array}{l}\text { Fattahi and } \\
\text { Khalilzadeh[38] }\end{array}$ & $\begin{array}{l}\text { Failure mode and effects analysis } \\
\text { (FMEA), MULTIMOORA, AHP } \\
\text { under fuzzy environment }\end{array}$ & Risk evaluation of steel industries factory \\
\hline Maghsoodi et al. [39] & $\begin{array}{l}\text { MULTIMOORA integrated } \\
\text { Shannon's entropy }\end{array}$ & $\begin{array}{l}\text { Selection of the best performance appraisal } \\
\text { methods }\end{array}$ \\
\hline Wang et al. [40] & $\begin{array}{l}\text { MULTIMOORA and Choquet } \\
\text { integral with triangular fuzzy } \\
\text { numbers }\end{array}$ & $\begin{array}{l}\text { Fine-Kinney based risk evaluation of ballast } \\
\text { tank maintenance }\end{array}$ \\
\hline Zarch et al. [41] & $\begin{array}{l}\text { SWARA based fuzzy } \\
\text { MULTIMOORA method }\end{array}$ & $\begin{array}{l}\text { Pharmacological therapy selection of type } 2 \\
\text { diabetes }\end{array}$ \\
\hline Liang et al. [42] & $\begin{array}{l}\text { SWARA based MULTIMOORA } \\
\text { with linguistic neutrosophic } \\
\text { numbers }\end{array}$ & Mining method selection \\
\hline Dorfeshan et al. [43] & $\begin{array}{l}\text { MULTIMOORA, MOOSRA, and } \\
\text { TPOP with interval type- } 2 \text { fuzzy } \\
\text { sets }\end{array}$ & $\begin{array}{l}\text { Selection of project critical path for aircraft } \\
\text { prototype batch and construction project }\end{array}$ \\
\hline Liao et al. [44] & $\begin{array}{l}\text { Unbalanced hesitant fuzzy linguistic } \\
\text { MULTIMOORA }\end{array}$ & $\begin{array}{l}\text { Investment selection case related to shared } \\
\text { bicycles in China }\end{array}$ \\
\hline Gündoğdu[45] & Spherical fuzzy MULTIMOORA & Personnel selection \\
\hline Lin et al. [46] & Picture fuzzy MULTIMOORA & Site selection for car sharing stations in Beijing \\
\hline Asante et al. [47] & MULTIMOORA-EDAS & $\begin{array}{l}\text { Exploring and ranking the barriers to } \\
\text { renewable energy adoption for Ghana }\end{array}$ \\
\hline Rahimi et al. [48] & $\begin{array}{l}\text { Fuzzy BWM, MULTIMOORA and } \\
\text { GIS }\end{array}$ & $\begin{array}{l}\text { Selecting sustainable landfill site for municipal } \\
\text { solid waste in Iran }\end{array}$ \\
\hline Tavana et al. [49] & FAHP, fuzzy MULTIMOORA & $\begin{array}{l}\text { Assessing supply chain risk-benefit and } \\
\text { supplier selection for a manufacturer of } \\
\text { consumer electronic goods in New Jersey }\end{array}$ \\
\hline Wu et al. [50] & $\begin{array}{l}\text { Cloud model theory based } \\
\text { MULTIMOORA }\end{array}$ & $\begin{array}{l}\text { Determining the ranking order of engineering } \\
\text { characteristics for electric vehicle } \\
\text { manufacturing organization }\end{array}$ \\
\hline $\begin{array}{l}\text { Tanriverdi and } \\
\text { Lezki[51] }\end{array}$ & FAHP based FTOPSIS & $\begin{array}{l}\text { Determining the best competition strategy for } \\
\text { air cargo carriers }\end{array}$ \\
\hline
\end{tabular}




\section{METHODOLOGY}

\subsection{Neutrosophic Set}

The fuzzy sets, proposed by Zadeh [52], use the membership function for dealing with complex decision-making problems that are associated with inaccuracies and unreliability. Some limitations associated with the use of one membership function are eliminated by using two functions: the membership function and the non-membership function, which is considered in intuitionistic and bipolar fuzzy sets. Neutrosophic Sets (NS) are proposed by Smarandache [15] with the degree of truth, indeterminacy, and falsity membership functions that are independent. Neutrosophic sets use three membership functions that can be used for expressing accuracy, indeterminacy, and inaccuracy during the evaluation of alternatives in multiple criteria decision-making. Using these membership functions, neutrosophic sets provide an efficient and flexible approach for evaluating alternatives even if decision-making problems are related to uncertainty and predictions.

A universe of discourse can be symbolized as $U$ and $x \in U . N$ as an NS can be identified by a truth $T_{N}(x)$ an indeterminacy $I_{N}(x)$ and falsity membership functions $F_{N}(x)$, and is shown like $N=\left\{<x: T_{N}(x), I_{N}(x), F_{N}(x)>x \in U\right\}$. Also, the functions of $T_{N}(x), I_{N}(x)$ and $F_{N}(x)$ are real standard or real nonstandard subsets of $] 0^{-}, 1^{+}$[and can be shown like $T, I, F: U \rightarrow] 0^{-}, 1^{+}\left[\right.$. The sum of the functions of $T_{N}(x), I_{N}(x)$ and $F_{N}(x)$ can be written as $0^{-}$ $\leq \sup _{N}(x)+\operatorname{supI}_{N}(x)+\operatorname{supF}_{N}(x) \leq 3^{+}$.

The complement of an NS Nis represented by $\mathrm{N}^{\mathrm{C}}$ and described as below:

$$
\begin{gathered}
T_{N}^{C}(x)=1^{+}{ }_{\Theta} T_{N}(x), \\
I_{N}^{C}(x)=1^{+}{ }_{\Theta} I_{N}(x), \\
F_{N}^{C}(x)=1^{+}{ }_{\Theta} F_{N}(x) \text { for all } x \in U .
\end{gathered}
$$

$N$ as NS is contained in other NS $P$ represents, $N \subseteq P$ if and only if $\inf T_{N}(x) \leq \inf T_{P}(x)$, $\sup _{N}(x) \leq \sup _{P}(x), \quad \operatorname{infI}_{N}(x) \geq \operatorname{infI}_{P}(x), \quad \operatorname{supI}_{N}(x) \geq \operatorname{supI}_{P}(x), \quad \operatorname{infF}_{N}(x) \geq \operatorname{infF}_{P}(x)$, $\sup _{N}(x) \geq \sup _{P}(x)$ for all $x \in U[71]$.

\subsection{Single valued neutrosophic sets (SVNS)}

SVNS are proposed by Wang et al. [64] for solving real-life problems in an uncertain environment. The interval of $[0,1]$ are considered for real-life applications rather than $] 0^{-}, 1^{+}[$. A universe of discourse can be symbolized as $U$ and $x \in U$. A SVNS $B$ in $U$ can be identified by a truth $T_{B}(x)$, an indeterminacy $I_{B}(x)$ and falsity membership functions $F_{B}(x)$. A SVNS $B$ can be shown as $B=\int_{x}<T_{B}(x), I_{B}(x), F_{B}(x)>/ x: x \in U$ for continuous values of $U$. On the other hand, an SVNS $B$ can be written as $B=\sum_{i}^{n}=1 \int_{x}<T_{B}(x), I_{B}(x), F_{B}(x)>/ x_{i}: x_{i} \in U$ for discrete values of $U$ [72]. $T_{B}(x), I_{B}(x)$ and $F_{B}(x)$ functions are real standard subsets of $[0,1]$ that is $T_{B}(x): U \rightarrow[0,1], I_{B}(x): U \rightarrow[0,1]$, and $F_{B}(x): U \rightarrow[0,1]$. Additionally, the sum of $T_{B}(x)$, $I_{B}(x)$ and $F_{B}(x)$, are in [0,3] and this can be written as $0 \leq T_{B}(x)+I_{B}(x)+F_{B}(x) \leq 3$ [73]. 
Let a single-valued neutrosophic triangular number $\tilde{a}=\left\langle\left(a_{1}, a_{2}, a_{3}\right) ; \alpha_{\tilde{a}}, \theta_{\tilde{a}}, \beta_{\tilde{a}}\right\rangle$ is a special neutrosophic set on $R$. Additionally $\alpha_{\tilde{a}}, \theta_{\tilde{a}}, \beta_{\tilde{a}} \in[0,1]$ and $a_{1}, a_{2}, a_{3} \in R$ where $a_{1} \leq a_{2} \leq a_{3}$. Truth, indeterminacy and falsity membership functions of this number can be computed as below [74-75]:

$$
\begin{gathered}
\mathrm{T}_{\tilde{a}}(\boldsymbol{x})=\left\{\begin{array}{cc}
\alpha_{\widetilde{\boldsymbol{a}}}\left(\frac{\mathrm{x}-a_{1}}{a_{2}-a_{1}}\right) & \left(a_{1} \leq x \leq a_{2}\right) \\
\alpha_{\widetilde{\boldsymbol{a}}} & \left(\mathrm{x}=a_{2}\right) \\
\alpha_{\tilde{a}}\left(\frac{a_{3}-x}{a_{3}-a_{2}}\right) & \left(a_{2}<x \leq a_{3}\right) \\
0 & \text { otherwise }
\end{array}\right. \\
\mathrm{I}_{\widetilde{\boldsymbol{a}}}(\boldsymbol{x})=\left\{\begin{array}{cc}
\left(\frac{a_{2}-\mathrm{x}+\theta_{\widetilde{a}}\left(\mathrm{x}-a_{1}\right)}{a_{2}-a_{1}}\right) & \left(a_{1} \leq x \leq a_{2}\right) \\
\theta_{\widetilde{\boldsymbol{a}}} & \left(\mathrm{x}=a_{2}\right) \\
\left(\frac{x-a_{2}+\theta_{\widetilde{a}}\left(a_{3}-x\right)}{a_{3}-a_{2}}\right) & \left(a_{2}<x \leq a_{3}\right) \\
1 & \text { otherwise }
\end{array}\right. \\
\mathrm{F}_{\widetilde{\boldsymbol{a}}}(\boldsymbol{x})=\left\{\begin{array}{cc}
\left(\frac{a_{2}-\mathrm{x}+\beta_{\widetilde{a}}\left(\mathrm{x}-a_{1}\right)}{a_{2}-a_{1}}\right) & \left(a_{1} \leq x \leq a_{2}\right) \\
\beta_{\widetilde{\boldsymbol{a}}} & \left(\mathrm{x}=a_{2}\right) \\
\left(\frac{x-a_{2}+\beta_{\tilde{a}}\left(a_{3}-x\right)}{a_{3}-a_{2}}\right) & \left(a_{2}<x \leq a_{3}\right) \\
1 & \text { otherwise }
\end{array}\right.
\end{gathered}
$$

According to the Eqs. (4-6) $\alpha_{\tilde{a}}, \theta_{\tilde{a}}$ and $\beta_{\tilde{a}}$ denote maximum truth, minimum indeterminacy and minimum falsity membership degrees, respectively.

Suppose $\tilde{a}=\left\langle\left(a_{1}, a_{2}, a_{3}\right) ; \alpha_{\tilde{a}}, \theta_{\tilde{a}}, \beta_{\tilde{a}}\right\rangle$ and $\tilde{n}=\left\langle\left(n_{1}, n_{2}, n_{3}\right) ; \alpha_{\tilde{n}}, \theta_{\tilde{n}}, \beta_{\tilde{n}}\right\rangle$ as two single-valued triangular neutrosophic numbers and $\lambda \neq 0$ as a real number. Considering the above-mentioned conditions addition of two single-valued triangular neutrosophic numbers are denoted as follows [74]:

$$
\tilde{a}+\tilde{n}=\left\langle\left(a_{1}+n_{1}, a_{2}+n_{2}, a_{3}+n_{3}\right) ; \alpha_{\tilde{a}} \wedge \alpha_{\tilde{n}}, \theta_{\tilde{a}} \vee \theta_{\tilde{n}}, \beta_{\tilde{a}} \vee \beta_{n}\right\rangle
$$

Subtraction of two single-valued triangular neutrosophic numbers is defined as Eq. (8):

$$
\tilde{a}-\tilde{n}=\left\langle\left(a_{1}-n_{3}, a_{2}-n_{2}, a_{3}-n_{1}\right) ; \alpha_{\tilde{a}} \wedge \alpha_{\tilde{n}}, \theta_{\tilde{a}} \vee \theta_{\tilde{n}}, \beta_{a} \vee \beta_{\tilde{n}}\right\rangle .
$$

The inverse of a single-valued triangular neutrosophic number $(\tilde{a} \neq 0)$ can be denoted as below:

$$
\tilde{a}^{-1}=\left\langle\left(\frac{1}{a_{3}}, \frac{1}{a_{2}}, \frac{1}{a_{1}}\right) ; \alpha_{\tilde{a}}, \theta_{\tilde{a}}, \beta_{\tilde{a}}\right\rangle .
$$

Multiplication of a single-valued triangular neutrosophic number by a constant value is represented as follows:

$$
\lambda \tilde{a}=\left\{\begin{array}{l}
\left\langle\left(\lambda a_{1}, \lambda a_{2}, \lambda a_{3}\right) ; \alpha_{\tilde{a}}, \theta_{\tilde{a}}, \beta_{\tilde{a}}\right\rangle \text { if }(\lambda>0) \\
\left\langle\left(\lambda a_{3}, \lambda a_{2}, \lambda a_{1}\right) ; \alpha_{\tilde{a}}, \theta_{\tilde{a}}, \beta_{\tilde{a}}\right\rangle \text { if }(\lambda<0)
\end{array} .\right.
$$


Division of a single-valued triangular neutrosophic number by a constant value are denoted as Eq. (11):

$$
\frac{\tilde{a}}{\lambda}=\left\{\begin{array}{l}
\left\langle\left(\frac{a_{1}}{\lambda}, \frac{a_{2}}{\lambda}, \frac{a_{3}}{\lambda}\right) ; \alpha_{\tilde{a}}, \theta_{\tilde{a}}, \beta_{\tilde{a}}\right\rangle \text { if }(\lambda>0) \\
\left\langle\left(\frac{a_{3}}{\lambda}, \frac{a_{2}}{\lambda}, \frac{a_{1}}{\lambda}\right) ; \alpha_{\tilde{a}}, \theta_{\tilde{a}}, \beta_{\tilde{a}}\right\rangle \text { if }(\lambda<0)
\end{array} .\right.
$$

Multiplication of two single-valued triangular neutrosophic numbers can be seen as follows:

$$
\tilde{a} \cdot \tilde{n}=\left\{\begin{array}{l}
\left\langle\left(b_{1} c_{1}, b_{2} c_{2}, b_{3} c_{3}\right) ; \alpha_{\tilde{a}} \wedge \alpha_{\tilde{n}}, \theta_{\tilde{a}} \vee \theta_{\tilde{n}}, \beta_{\tilde{a}} \vee \beta_{\tilde{n}}\right\rangle \text { if }\left(b_{3}>0, c_{3}>0\right) \\
\left\langle\left(b_{1} c_{3}, b_{2} c_{2}, b_{3} c_{1}\right) ; \alpha_{\tilde{a}} \wedge \alpha_{\tilde{n}}, \theta_{\tilde{a}} \vee \theta_{\tilde{n}}, \beta_{\tilde{a}} \vee \beta_{\tilde{n}}\right\rangle \text { if }\left(b_{3}<0, c_{3}>0\right) . \\
\left\langle\left(b_{3} c_{3}, b_{2} c_{2}, b_{1} c_{1}\right) ; \alpha_{\tilde{a}} \wedge \alpha_{\tilde{n}}, \theta_{\tilde{a}} \vee \theta_{\tilde{n}}, \beta_{\tilde{a}} \vee \beta_{\tilde{n}}\right\rangle \text { if }\left(b_{3}<0, c_{3}<0\right)
\end{array}\right.
$$

Division of two single-valued triangular neutrosophic numbers can be denoted as Eq. (13):

$$
\frac{\tilde{a}}{\tilde{n}}=\left\{\begin{array}{l}
\left\langle\left(\frac{a_{1}}{n_{3}}, \frac{a_{2}}{n_{2}}, \frac{a_{3}}{n_{1}}\right) ; \alpha_{\tilde{a}} \wedge \alpha_{\tilde{n}}, \theta_{\tilde{a}} \vee \theta_{\tilde{n}}, \beta_{a} \vee \beta_{\tilde{n}}\right\rangle \text { if }\left(a_{3}>0, n_{3}>0\right) \\
\left\langle\left(\frac{a_{3}}{n_{3}}, \frac{a_{2}}{n_{2}}, \frac{a_{1}}{n_{1}}\right) ; \alpha_{\tilde{a}} \wedge \alpha_{\tilde{n}}, \theta_{\tilde{a}} \vee \theta_{\tilde{n}}, \beta_{\tilde{a}} \vee \beta_{\tilde{n}}\right\rangle \text { if }\left(a_{3}<0, n_{3}>0\right) \\
\left\langle\left(\frac{a_{3}}{n_{1}}, \frac{a_{2}}{n_{2}}, \frac{a_{1}}{n_{3}}\right) ; \alpha_{\tilde{a}} \wedge \alpha_{\tilde{n}}, \theta_{\tilde{a}} \vee \theta_{\tilde{n}}, \beta_{\tilde{a}} \vee \beta_{\tilde{n}}\right\rangle \text { if }\left(a_{3}<0, n_{3}<0\right)
\end{array}\right.
$$

Score function $\left(s_{a}\right)$ for a single-valued triangular neutrosophic number $a=\left(a_{1}, a_{2}, a_{3}\right)$ can be found as below [76-77]:

$$
s_{a}=\left(1+a_{1}-2 * a_{2}-a_{3}\right) / 2,
$$

where $s_{a} \in[-1,+1]$.

The maximum distance $e_{\max }(a, n)$ between two single-valued triangular neutrosophic numbers such as $a=\left(a_{1}, a_{2}, a_{3}\right)$ and $n=\left(n_{1}, n_{2}, n_{3}\right)$ can be computed as follows [76]:

$$
e_{\text {max }}(a, n)= \begin{cases}\left|a_{1}-n_{1}\right| & a_{1}, n_{1} \in \Omega_{\max } \\ \left|a_{3}-n_{3}\right| & a_{3}, n_{3} \in \Omega_{\min }\end{cases}
$$

\subsection{Neutrosophic AHP}

Steps of neutrosophic AHP can be explained as follows [74-75]:

1. Decision problem is constructed as a hierarchical view consisting of goal, criteria, sub-criteria and alternatives, respectively.

2. Pairwise comparisons are made to form a neutrosophic evaluation matrix composed of triangular neutrosophic numbers representing decision-makers' views. Neutrosophic pairwise evaluation matrix $(\tilde{O})$ is seen as below:

$$
\tilde{O}=\left[\begin{array}{cccc}
\tilde{1} & \tilde{o}_{12} & \cdots & \tilde{o}_{1 n} \\
\vdots & \vdots & \vdots & \vdots \\
\tilde{o}_{n 1} & \tilde{o}_{n 2} & \cdots & \tilde{1}
\end{array}\right]
$$

According to Eq. (16), $\tilde{o}_{j i}=\left(\tilde{o}_{i j}\right)^{-1}$ is valid.

3. Neutrosophic pairwise evaluation matrix is constructed by using scale arranged for the neutrosophic environment such as Table 3: 
Table 3 AHP scale transformed for neutrosophic triangular numbers

\begin{tabular}{clc}
\hline Value & Explanation & Neutrosophic triangular scale \\
\hline 1 & Equally influential & $\tilde{1}=\langle(1,1,1) ; 0.5,0.5,0.5\rangle$ \\
3 & Slightly influential & $\tilde{3}=\langle(2,3,4) ; 0.3,0.75,0.7\rangle$ \\
5 & Strongly influential & $\tilde{5}=\langle(4,5,6) ; 0.8,0.15,0.2\rangle$ \\
7 & Very strongly influential & $\tilde{7}=\langle(6,7,8) ; 0.9,0.1,0.1\rangle$ \\
9 & Absolutely influential & $\tilde{9}=\langle(9,9,9) ; 1,0,0\rangle$ \\
2 & Intermediate values & $\tilde{2}=\langle(1,2,3) ; 0.4,0.65,0.6\rangle$ \\
4 & between two close scales & $\tilde{4}=\langle(3,4,5) ; 0.6,0.35,0.4\rangle$ \\
6 & & $\tilde{6}=\langle(5,6,7) ; 0.7,0.25,0.3\rangle$ \\
8 & & $\tilde{8}=\langle(7,8,9) ; 0.85,0.1,0.15\rangle$ \\
\hline
\end{tabular}

4. Neutrosophic pairwise evaluation matrix is changed to deterministic pairwise evaluation matrix for obtaining the weights of criterion as follows:

Let $\tilde{o}_{i j}=\left\langle\left(d_{1}, e_{1}, f_{l}\right) ; \alpha_{\tilde{o}}, \theta_{\tilde{o}}, \beta_{\tilde{o}}\right)$ be a single-valued neutrosophic number, then the score and accuracy degrees of $\tilde{\mathrm{o}}_{\mathrm{ij}}$ are computed as the following equations:

$$
\begin{aligned}
& S\left(\tilde{o}_{i j}\right)=\frac{1}{16}\left[d_{1}+e_{1}+f_{1}\right] x\left(2+\alpha_{\tilde{o}}-\theta_{\tilde{o}}-\beta_{\tilde{o}}\right), \\
& A\left(\tilde{o}_{i j}\right)=\frac{1}{16}\left[d_{1}+e_{1}+f_{1}\right] x\left(2+\alpha_{\tilde{o}}-\theta_{\tilde{o}}+\beta_{\tilde{o}}\right) .
\end{aligned}
$$

In order to obtain the score and accuracy degree of $\tilde{o}_{i j}$, the following equations are used.

$$
\begin{aligned}
& S\left(\tilde{o}_{j i}\right)=1 / S\left(\tilde{o}_{i j}\right), \\
& A\left(\tilde{o}_{j i}\right)=1 / A\left(\tilde{o}_{i j}\right) .
\end{aligned}
$$

The deterministic pairwise evaluation matrix is constructed with compensation by score value in the neutrosophic pairwise evaluation matrix. The obtained deterministic matrix can be seen as follows:

$$
O=\left[\begin{array}{cccc}
1 & o_{12} & \cdots & o_{1 n} \\
\vdots & \vdots & \vdots & \vdots \\
o_{n 1} & o_{n 2} & \cdots & 1
\end{array}\right]
$$

Ranking of priorities as eigenvector $X$ is obtained according to the following steps:

a) Firstly column entries are normalized by dividing each entry to the sum of column

b) Then row averages are summed.

5. Consistency index $(C I)$ and consistency ratio $(C R)$ values are computed for measuring the inconsistency for decision-makers' judgments in the entire pairwise evaluation matrix. If $C R$ is greater than 0.1 , the process should be repeated due to unreliable decisionmakers' judgments.

CI is computed according to the following steps:

a) Each value in the first column of the pairwise evaluation matrix is multiplied by the priority of the first criterion and this process is applied for all columns. Values are summed across the rows to construct the weighted sum vector.

b) The elements of the weighted sum vector are divided by corresponding to the priority of each criterion. Then the average of values are acquired and represented by $\lambda_{\max }$.

c) The value of $C I$ is calculated as Eq. (22): 


$$
C I=\frac{\lambda_{\max }-n}{n-1} .
$$

According to Eq. (7), the number of elements being compared is denoted by $n$.

After the value of $C I$ is found, $C R$ is computed as follows:

$$
C R=\frac{C I}{R I}
$$

where $R I$ denotes the consistency index for randomly generated pairwise evaluation matrix and can be shown as Table 4 .

Table 4 RI table used for computing CR value

\begin{tabular}{lcccccccccc}
\hline Order of random matrix $(n)$ & 1 & 2 & 3 & 4 & 5 & 6 & 7 & 8 & 9 & 10 \\
\hline Related $R I$ value & 0 & 0 & 0.58 & 0.9 & 1.12 & 1.24 & 1.32 & 1.4 & 1.45 & 1.49 \\
\hline
\end{tabular}

6. Overall priority values for each alternative are computed and the ranking process is applied.

\subsection{MULTIMOORA method}

The MULTIMOORA method developed by Brauers and Zavadskas [31] includes three approaches for ranking alternatives. These approaches are Ratio System (RS), Reference Point (RF), and the Full Multiplicative Form (FMF), respectively. The decision about selecting the best alternative is made according to the theory of dominance for three approaches [78-81].

The overall importance of alternative $i$ in ratio system approach is given as [76]:

$$
\begin{gathered}
z_{i}=z_{i}^{+}-z_{i}^{-}, \\
z_{i}^{+}=\sum_{j \in \Omega_{\max } w_{j}} p_{i j} \\
z_{i}^{-}=\sum_{j \in \Omega_{\text {min }} w_{j}} p_{i j}, \\
p_{i j}=\frac{x_{i j}}{\sqrt{\sum_{i=1}^{n} x_{i j}^{2}}} .
\end{gathered}
$$

According to Eqs. (24)-(27) $z_{i}^{+}$and $z_{i}{ }^{-}$show overall importance of alternative $i$ acquired for benefit and cost criteria; $p_{i j}$ describes the normalized performance of alternative $i$ in terms of criterion $j ; x_{i j}$ shows the performance of alternative $i$ related with criterion $j$; sets of benefit and cost criteria are represented by $\Omega_{\max }$ and $\Omega_{\min }$; the weight of criterion $j$ is denoted by $w_{j}$. In terms of ratio system, approach alternatives are ranked in terms of decreasing $z_{i}$ values.

According to the reference point approach optimization is shown as Eq. (28):

$$
e_{i}^{\max }=\max _{j}\left(w_{j}\left|p_{j}^{*}-p_{i j}\right|\right) \text {. }
$$

The maximum distance of alternative $i$ to the reference point is shown by $e_{\max }{ }^{i}$ and the coordinate $j$ of the reference point is denoted by $p_{j}{ }^{*}$ and obtained as below:

$$
p_{j}^{*}=\left\{\begin{array}{ll}
\max _{i} p_{i j} & j \in \Omega_{\max } \\
\min _{i} p_{i j} & j \in \Omega_{\min }
\end{array} .\right.
$$


In terms of reference point, approach alternatives are ranked according to increasing $e_{\max }{ }^{i}$ values.

The overall utility of the alternative in the full multiplicative form is obtained as:

$$
\begin{gathered}
o u_{i}=\frac{c_{i}}{d_{i}}, \\
c_{i}=\prod_{j \in \Omega_{\text {max }}} w_{j} p_{i j}, \\
d_{i}=\prod_{j \in \Omega_{\text {min }}} w_{j} p_{i j} .
\end{gathered}
$$

According to Eqs. (30-32) while the product of the weighted performance ratings of benefit criteria for alternative $i$ is represented by $c_{i}, d_{i}$ can be used for cost criteria. In terms of full multiplicative form approach alternatives are ranked in terms of decreasing $o u_{i}$ values.

The ranking list related to three approaches is constructed and the decision is made by considering the theory of dominance [32, 82-85].

\subsection{Single Valued Neutrosophic Sets Based MULTIMOORA Method}

SVNS based MULTIMOORA method can be applied for decision problems consisting of $m$ alternatives and $n$ criteria, and the performances of alternatives are considered by using SVNS. Steps of SVNS based MULTIMOORA method for ratio system approach are expressed as below [76]:

1. By using a single-valued neutrosophic weighted average operator the values of $Z_{i}^{+}$and $Z_{i}^{-}$are computed as below:

$$
\begin{aligned}
& Z_{i}^{+}=\left(1-\prod_{j \in \Omega_{\max }}\left(1-t_{j}\right)^{w_{j}}, \prod_{j \in \Omega_{\max }}\left(i_{j}\right)^{w_{j}}, \prod_{j \in \Omega_{\max }}\left(f_{j}\right)^{w_{j}}\right), \\
& Z_{i}^{-}=\left(1-\prod_{j \in \Omega_{\min }}\left(1-t_{j}\right)^{w_{j}}, \prod_{j \in \Omega_{\min }}\left(i_{j}\right)^{w_{j}}, \prod_{j \in \Omega_{\min }}\left(f_{j}\right)^{w_{j}}\right) .
\end{aligned}
$$

The importance of alternative $i$ acquired for benefit and cost criteria are represented by $Z_{i}^{+}$and $Z_{i}^{-}$as single-valued neutrosophic numbers.

2. Then the values of $z_{i}^{+}$and $z_{i}{ }^{-}$are computed via score function as Eqs. (35) and (36):

$$
\begin{aligned}
& z_{i}^{+}=s\left(Z_{i}^{+}\right), \\
& z_{i}^{-}=s\left(Z_{i}^{-}\right) .
\end{aligned}
$$

3. The overall importance for each alternative is obtained as below:

$$
z_{i}=z_{i}^{+}-z_{i}^{-} .
$$

4. Alternatives are ranked in terms of decreasing $z_{i}$ values.

The steps of SVNS based MULTIMOORA method for reference point approach are stated as below [76]:

1. As a single-valued neutrosophic number each coordinate of the reference point is written by $p^{*}=\left\{p_{1}{ }^{*}, p_{2}{ }^{*}, \ldots, p_{n}{ }^{*}\right\}$ and $p_{j}{ }^{*}=\left\langle t_{j}{ }^{*}, i_{j}, f_{j}{ }^{*}\right\rangle$ values are acquired as Eq. (38):

$$
p_{j}^{*}=\left\{\begin{array}{ll}
\left\langle\max _{i} t_{i j}, \min _{i} i_{i j}, \min _{i} f_{i j}\right\rangle & j \in \Omega_{\max } \\
\left\langle\min _{i} t_{i j}, \min _{i} i_{i j}, \max _{i} f_{i j}\right\rangle & j \in \Omega_{\min }
\end{array} .\right.
$$


Coordinate $j$ of the reference point can be written as $p_{j}{ }^{*}$ :

$$
p_{j}^{*}=\left\{\begin{array}{lll}
\langle 1,0,0\rangle & j \in \Omega_{\max } \\
\langle 0,0,1\rangle & j \in \Omega_{\min }
\end{array} .\right.
$$

2. Maximum distance from each alternative to all coordinates of the reference point is calculated by using Eq. (40):

$$
e_{i j}^{\max }=e_{\max }\left(p_{i j}, p_{j}^{*}\right) w_{j} .
$$

3. Maximum distance of each alternative is computed via Eq. (41):

$$
e_{i}^{\max }=\max _{j} e_{i j}^{\max } .
$$

Then alternatives are ranked in terms of increasing $I_{M A X}$ values.

The steps of SVNS based MULTIMOORA method for a full multiplicative form approach are explained as follows [76]:

1. The values of $C_{i}$ and $D_{i}$ are calculated as follows:

$$
\begin{aligned}
C_{i} & =\left(\prod_{j \in \Omega_{\max }}\left(t_{j}\right)^{w_{j}}, 1-\prod_{j \in \Omega_{\max }}\left(1-i_{j}\right)^{w_{j}}, 1-\prod_{j \in \Omega_{\max }}\left(1-f_{j}\right)^{w_{j}}\right), \\
D_{i} & =\left(\prod_{j \in \Omega_{\min }}\left(t_{j}\right)^{w_{j}}, 1-\prod_{j \in \Omega_{\min }}\left(1-i_{j}\right)^{w_{j}}, 1-\prod_{j \in \Omega_{\min }}\left(1-f_{j}\right)^{w_{j}}\right) .
\end{aligned}
$$

As single-valued neutrosophic numbers $C_{i}$ and $D_{i}$ can be written as $C_{i}=\left\langle t_{C i}, i_{C i}, f_{C i}\right\rangle$ and $D_{i}=\left\langle t_{D i}, i_{D i}, f_{D i}\right\rangle$, respectively.

2. The values of $c_{i}$ and $d_{i}$ are computed via score function as Eqs. (44) and (45):

$$
\begin{aligned}
c_{i} & =s\left(C_{i}\right), \\
d_{i} & =s\left(D_{i}\right) .
\end{aligned}
$$

3. The overall utility for each alternative is obtained as below:

$$
o u_{i}=\frac{c_{i}}{d_{i}}
$$

Alternatives are ranked in terms of decreasing $o u_{i}$ values and final ranking related to alternatives are made via the theory of dominance in terms of MULTIMOORA method.

\section{CASE STUDY AND RESUlTS}

In this study, nine criteria for choosing the optimal training aircraft for FTOs are determined according to literature review [7, 8, 18] and experts' opinions. Additionally, they are weighted via single-valued neutrosophic AHP firstly. For this purpose evaluations of 10 decision-makers related to the selection of training aircraft are considered in terms of the group decision-making (GDM) process. The required criteria are: runway length, capable of IFR/VFR operations, reliability/security, purchasing cost, maintenance cost, operational cost, certified staff number, availability of facilities and ease of finding spare part, respectively. While some of the criteria are common (purchasing cost, maintenance cost, operational cost, reliability/security), the other criteria are specified and diversified according to the purpose and mission for military, commercial, passenger and cargo aircraft types. 
The neutrosophic evaluation matrix in terms of the criteria considered for the selection of training aircraft is constructed through decision-makers' linguistic judgments which are seen as Table 3. A part of the neutrosophic evaluation matrix for the criteria are shown in Appendix 1.

After that, the neutrosophic evaluation matrix is transformed into a crisp one by using Eq. (17) and taking the geometric means of 10 decision-makers' judgments. The crisp evaluation matrix for criteria is shown in Table 5.

Table 5 The crisp evaluation matrix for criteria

\begin{tabular}{lccccccccc}
\hline Criteria & $\begin{array}{c}\text { Required } \\
\text { runway } \\
\text { length }\end{array}$ & $\begin{array}{c}\text { Capable } \\
\text { of } \\
\text { IFR/VFR } \\
\text { operations }\end{array}$ & $\begin{array}{c}\text { Reliability/ } \\
\text { safety }\end{array}$ & $\begin{array}{c}\text { Purchasing } \\
\text { cost }\end{array}$ & $\begin{array}{c}\text { Maintenance } \\
\text { cost }\end{array}$ & $\begin{array}{c}\text { Operational } \\
\text { cost }\end{array}$ & $\begin{array}{c}\text { Certified } \\
\text { staff } \\
\text { number }\end{array}$ & $\begin{array}{c}\text { Availability } \\
\text { of facilities }\end{array}$ & $\begin{array}{c}\text { Ease of } \\
\text { finding } \\
\text { spare part }\end{array}$ \\
\hline $\begin{array}{l}\text { Required runway } \\
\text { length }\end{array}$ & 1 & 0.773 & 1.0200 & 0.8695 & 1.1133 & 1.2563 & 0.4357 & 0.8855 & 0.591 \\
$\begin{array}{l}\text { Capable of IFR/VFR } \\
\text { operations }\end{array}$ & 1.2922 & 1 & 1.1298 & 2.0885 & 2.0296 & 1.2228 & 1.3450 & 0.9182 & 0.715 \\
$\begin{array}{l}\text { Reliability/safety } \\
\text { Purchasing cost }\end{array}$ & 1.9803 & 0.8850 & 1 & 1.5795 & 1.0079 & 0.8103 & 0.3959 & 0.5376 & 0.663 \\
$\begin{array}{l}\text { Maintenance cost } \\
\text { Operational cost }\end{array}$ & 0.8981 & 0.4787 & 0.6330 & 1 & 0.6413 & 0.9892 & 0.8545 & 0.5830 & 1.247 \\
$\begin{array}{l}\text { Certified staff } \\
\text { number }\end{array}$ & 0.7959 & 0.8177 & 1.2340 & 1.0108 & 1.0818 & 1 & 1.0153 & 0.5583 & 1.428 \\
$\begin{array}{l}\text { Availability of } \\
\text { facilities }\end{array}$ & 1.1294 & 0.743 & 2.5254 & 1.1702 & 1.194 & 0.9849 & 1 & 0.7840 & 1.288 \\
$\begin{array}{l}\text { Ease of finding spare } \\
\text { part }\end{array}$ & 1.6901 & 1.0890 & 1.8600 & 1.7149 & 1.4807 & 1.7909 & 1.2754 & 1 & 1.256 \\
\hline
\end{tabular}

The normalized evaluation matrix for criteria is formed as Table 6.

Table 6 The normalized evaluation matrix for criteria

\begin{tabular}{|c|c|c|c|c|c|c|c|c|c|}
\hline Criteria & $\begin{array}{l}\text { Required } \\
\text { runway } \\
\text { length }\end{array}$ & $\begin{array}{c}\text { Capable of } \\
\text { IFR/VFR } \\
\text { operations }\end{array}$ & $\begin{array}{l}\text { Reliability } \\
\text { /safety }\end{array}$ & $\begin{array}{l}\text { Purchasing } \\
\text { cost }\end{array}$ & $\begin{array}{l}\text { Maintenance } \\
\text { cost }\end{array}$ & $\begin{array}{l}\text { Operational } \\
\text { cost }\end{array}$ & $\begin{array}{l}\text { Certified } \\
\text { staff } \\
\text { number }\end{array}$ & $\begin{array}{l}\text { Availability } \\
\text { of facilities }\end{array}$ & $\begin{array}{c}\text { Ease of } \\
\text { finding } \\
\text { spare part }\end{array}$ \\
\hline $\begin{array}{l}\text { Required runway } \\
\text { length }\end{array}$ & 0.0890 & 0.1007 & 0.0857 & 0.0737 & 0.1030 & 0.1298 & 0.0549 & 0.1314 & 0.065 \\
\hline $\begin{array}{l}\text { Capable of } \\
\text { IFR/VFR operations }\end{array}$ & 0.1150 & 0.1302 & 0.0949 & 0.1770 & 0.1877 & 0.1263 & 0.1695 & 0.1362 & 0.079 \\
\hline Reliability/safety & 0.0872 & 0.1152 & 0.0840 & 0.1339 & 0.093 & 0.0837 & 0.0498 & 0.0797 & 0.073 \\
\hline Purchasing cost & 0.1024 & 0.0623 & 0.0531 & 0.0847 & 0.0593 & 0.1022 & 0.1076 & 0.086 & 0.138 \\
\hline Maintenance cost & 0.0799 & 0.0641 & 0.0833 & 0.1322 & 0.0925 & 0.0954 & 0.1055 & 0.1002 & 0.088 \\
\hline Operational cost & 0.070 & 0.1065 & 0.1036 & 0.0857 & 0.1000 & 0.1033 & 0.1279 & 0.0828 & 0.158 \\
\hline $\begin{array}{l}\text { Certified staff } \\
\text { number }\end{array}$ & 0.2043 & 0.0968 & 0.2121 & 0.099 & 0.1104 & 0.1017 & 0.1260 & 0.116 & 0.143 \\
\hline $\begin{array}{l}\text { Availability of } \\
\text { facilities }\end{array}$ & 0.1005 & 0.1418 & 0.1562 & 0.1454 & 0.1369 & 0.1850 & 0.1607 & 0.1484 & 0.139 \\
\hline $\begin{array}{l}\text { Ease of finding } \\
\text { spare part }\end{array}$ & 0.1504 & 0.1819 & 0.1266 & 0.0679 & 0.1165 & 0.0723 & 0.0977 & 0.1180 & 0.111 \\
\hline
\end{tabular}

Finally, the priorities for the criteria as eigenvector $X$ can be calculated by taking the overall row averages and seen as below: 


$$
X=\left[\begin{array}{c}
0.092695 \\
0.13521 \\
0.088997 \\
0.088593 \\
0.093533 \\
0.104439 \\
0.134509 \\
0.146125 \\
0.1159
\end{array}\right]
$$

According to eigenvector $X$, while the number of maintenance facilities was found as the most important criterion having a value of 0.146125 , the historical cost was obtained as the least important one having a value of 0.088593 .

Then the consistency of decision-makers' judgments is checked by computing $C I$ and $C R$ values. $C I$ value is found as 0.037 and by using Eq. (23) $C R$ value is acquired as 0.025 . Decision-makers' evaluations are consistent because of having $C R$ value smaller than 0.1 .

After obtaining the criteria weights, alternatives have been chosen among the most commonly used aircraft by FTOs in Turkey. Besides, ninety percent of aircraft used for flight training is of a single-engine type [86]. Therefore, only six single-engine type aircraft (Diamond 40, Evektor, The Tecnam, Pipera, Diamond 20 and Cessna 172) have been included as alternatives in the research according to the experts' views in terms of training aircrafts. Alternatives are ranked via single-valued neutrosophic sets based on MULTIMOORA method.

Firstly neutrosophic evaluations of six training aircraft obtained by taking the geometric means of 10 decision-makers' judgments are presented in Appendix 2.

Then in terms of ratio system approach the values of $Z_{i}^{+}, Z_{i}^{-}, z_{i}^{+}, z_{i}^{-}$and $z_{i}$ are computed and training planes are ranked as seen in Table 7.

Table 7 Ranking of training aircraft according to the ratio system approach

\begin{tabular}{lcccccc}
\hline & $Z_{i}^{+}$ & $Z_{i}^{-}$ & $z_{i}^{+}$ & $z_{i}^{-}$ & $z_{i}$ & Ranking \\
\hline Diamond 40 & $(0.63,0.35,0.37)$ & $(0.33,0.66,0.67)$ & 0.273404 & -0.33757 & 0.610969 & 3 \\
Evektor & $(0.62,0.37,0.38)$ & $(0.32,0.66,0.68)$ & 0.242802 & -0.33344 & 0.576242 & 5 \\
The tecnam & $(0.67,0.31,0.33)$ & $(0.33,0.65,0.67)$ & 0.360386 & -0.31666 & 0.677044 & 2 \\
Pipera & $(0.63,0.33,0.37)$ & $(0.34,0.64,0.66)$ & 0.298661 & -0.30727 & 0.605931 & 4 \\
Diamond 20 & $(0.47,0.5,0.53)$ & $(0.25,0.72,0.75)$ & -0.02318 & -0.47464 & 0.451462 & 6 \\
Cessna 172 & $(0.63,0.34,0.37)$ & $(0.29,0.68,0.71)$ & 0.298632 & -0.38994 & 0.688570 & 1 \\
\hline
\end{tabular}

According to Table 7 ranking of training aircraft is Cessna $172>$ The tecnam > Diamond $40>$ Pipera $>$ Evektor $>$ Diamond 20 in terms of ratio system approach.

In addition, the ranking of training aircraft is presented in Table 8 in terms of the reference point approach. 
Table 8 Ranking of training aircraft according to the reference point approach

\begin{tabular}{lccccccccccc}
\hline & $p_{1}^{*}$ & $p_{2}^{*}$ & $p_{3}^{*}$ & $p_{4}^{*}$ & $p_{5}^{*}$ & $p_{6}^{*}$ & $p_{7}^{*}$ & $p_{8}^{*}$ & $p_{9}^{*}$ & $e_{i}^{\text {max }}$ & Ranking \\
\hline Diamond 40 & 0.02 & 0.033 & 0.020 & 0.069 & 0.074 & 0.06 & 0.030 & 0.052 & 0.01 & 0.07 & 1 \\
Evektor & 0.02 & 0.023 & 0.040 & 0.067 & 0.063 & 0.08 & 0.053 & 0.029 & 0.02 & 0.08 & 4 \\
The tecnam & 0.02 & 0.031 & 0.019 & 0.068 & 0.065 & 0.08 & 0.020 & 0.054 & 0.01 & 0.08 & 5 \\
Pipera & 0.03 & 0.040 & 0.017 & 0.071 & 0.060 & 0.08 & 0.030 & 0.036 & 0.02 & 0.08 & 6 \\
Diamond 20 & 0.02 & 0.050 & 0.036 & 0.052 & 0.061 & 0.06 & 0.073 & 0.080 & 0.03 & 0.08 & 3 \\
Cessna 172 & 0.02 & 0.0360 & 0.0217 & 0.0623 & 0.0645 & 0.07 & 0.028 & 0.040 & 0.02 & 0.07 & 2 \\
\hline
\end{tabular}

According to Table 8, the ranking of training aircraft is Diamond $40>$ Cessna $172>$ Diamond $20>$ Evektor $>$ The tecnam > Pipera in terms of reference point approach.

In terms of the full multiplicative form approach the values of $C_{i}, D_{i}, c_{i}, d_{i}$ and $o u_{i}$ are computed and training aircraft are ranked seen as Table 9.

Table 9 Ranking of training aircraft according to the full multiplicative form approach

\begin{tabular}{lcccccc}
\hline & $C_{i}$ & $D_{i}$ & $c_{i}$ & $d_{i}$ & ou $_{i}$ & Ranking \\
\hline Diamond 40 & $(0.8,0.18,0.2)$ & $(0.92,0.08,0.08)$ & 0.621453 & 0.836481 & 0.742937 & 4 \\
Evektor & $(0.79,0.21,0.21)$ & $(0.92,0.07,0.08)$ & 0.580427 & 0.842982 & 0.688540 & 5 \\
The tecnam & $(0.83,0.16,0.17)$ & $(0.92,0.07,0.08)$ & 0.668086 & 0.851028 & 0.785034 & 2 \\
Pipera & $(0.81,0.16,0.19)$ & $(0.92,0.07,0.08)$ & 0.650124 & 0.84683 & 0.767714 & 3 \\
Diamond 20 & $(0.67,0.32,0.33)$ & $(0.88,0.11,0.12)$ & 0.347624 & 0.768949 & 0.452076 & 6 \\
Cessna 172 & $(0.82,0.16,0.18)$ & $(0.9,0.08,0.1)$ & 0.656703 & 0.819214 & 0.801625 & 1 \\
\hline
\end{tabular}

According to Table 9, ranking of training aircraft is Cessna $172>$ The tecnam > Pipera > Diamond $40>$ Evektor $>$ Diamond 20 in terms of a full multiplicative form approach.

The final ranking of training aircraft according to the SVNS based MULTIMOORA method by considering three different approaches is presented in Table 10.

Table 10 The final ranking of training aircraft according to the single-valued neutrosophic sets based MULTIMOORA method

\begin{tabular}{lcccc}
\hline & $\begin{array}{c}\text { Ranking for ratio } \\
\text { system approach }\end{array}$ & $\begin{array}{c}\text { Ranking for } \\
\text { reference point } \\
\text { approach }\end{array}$ & $\begin{array}{c}\text { Ranking for a full } \\
\text { multiplicative form } \\
\text { approach }\end{array}$ & $\begin{array}{c}\text { Final ranking based } \\
\text { on dominance theory }\end{array}$ \\
\hline Diamond 40 & 3 & 1 & 4 & 3 \\
Evektor & 5 & 4 & 5 & 5 \\
The tecnam & 2 & 5 & 2 & 2 \\
Pipera & 4 & 6 & 3 & 4 \\
Diamond 20 & 6 & 3 & 6 & 6 \\
Cessna 172 & 1 & 2 & 1 & 1 \\
\hline
\end{tabular}

According to Table 10, three different approaches give different ranking results and the final ranking for dominance theory is Cessna 172> The tecnam > Diamond $40>$ Pipera $>$ Evektor $>$ Diamond 20 like ratio system approach. 


\section{COMPARISON AND SENSITIVITY ANALYSIS}

In this section, the results of the proposed approach are analyzed based on a comparison and a sensitivity analysis.

\subsection{Comparison with the neutrosophic AHP-TOPSIS method}

Here, a comparison was performed between the results attained from the neutrosophic AHP-MULTIMOORA method and those of another approach. To show the efficiency and display the irreplaceable merits of the neutrosophic AHP-MULTIMOORA method, the AHP-TOPSIS method [87] is implemented to handle the decision making problem.

Let $p_{i j}$ be the neutrosophic number that describes the normalized performance of alternative $i$ in terms of criterion $j$; sets of benefit and cost criteria are represented by $\Omega_{\max }$ and $\Omega_{\min }$; weight of criterion $j$ is denoted by $w_{j}$. In the AHP-TOPSIS approach, the computation of an ideal solution (IS) and anti-ideal solution (A-IS) of each criterion are important concerns for DEs. At this time, IS and A-IS are computed with reference to the neutrosophic fuzzy IS (NF-IS) and A-IS (NFA-IS). Let $p_{j}{ }^{+}$and $p_{j}{ }^{-}$denote the NF-IS and NFA-IS and are calculated using the following formula

$$
\begin{aligned}
& p_{j}^{+}=\left(t_{i j}^{+}, i_{i j}^{+}, f_{i j}^{+}\right)=\left\{\begin{array}{ll}
\left\langle\max _{i} t_{i j}, \min _{i} i_{i j}, \min _{i} f_{i j}\right\rangle & j \in \Omega_{\max } \\
\left\langle\min _{i} t_{i j}, \min _{i} i_{i j}, \max _{i} f_{i j}\right\rangle & j \in \Omega_{\min }
\end{array},\right. \\
& p_{j}^{-}=\left(t_{i j}^{-}, i_{i j}^{-}, f_{i j}^{-}\right)= \begin{cases}\left\langle\min _{i} t_{i j}, \min _{i} i_{i j}, \max _{i} f_{i j}\right\rangle & j \in \Omega_{\max } \\
\left\langle\max _{i} t_{i j}, \min _{i} i_{i j}, \min _{i} f_{i j}\right\rangle & j \in \Omega_{\min }\end{cases}
\end{aligned}
$$

Next, calculate the distance measures with the Euclidean distance [87]. The separation to the ideal alternative and distance to the anti-ideal alternative are denoted by

$$
\begin{gathered}
d\left(p_{i j}, p_{j}^{+}\right)=\frac{1}{3} \sum_{j=1}^{n} w_{j}\left[\left|t_{i j}-t_{i j}^{+}\right|+\left|i_{i j}-i_{i j}^{+}\right|+\left|f_{i j}-f_{i j}^{+}\right|\right], \\
\left(p_{i j}, p_{j}^{-}\right)=\frac{1}{3} \sum_{j=1}^{n} w_{j}\left[\left|t_{i j}-t_{i j}^{-}\right|+\left|i_{i j}-i_{i j}^{-}\right|+\left|f_{i j}-f_{i j}^{-}\right|\right] .
\end{gathered}
$$

Now, compute the relative closeness to the ideal alternative and rank the preference order. The relative closeness of the $i^{\text {th }}$ to the ideal alternative concerning the ideal alternative is as follows:

$$
C_{i}=\frac{d\left(p_{i j}, p_{j}^{-}\right)}{d\left(p_{i j}, p_{j}^{-}\right)+d\left(p_{i j}, p_{j}^{+}\right)} ; C_{i} \in[0,1] .
$$

A set of alternatives that can be preference are ranked according to the descending order of $C_{i} \in[0,1]$; then larger means a better alternative.

From Appendix 2 and Eqs. (47)-(48), NF-IS and NFA-IS are evaluated. Now, the whole computational results of neutrosophic AHP-TOPSIS [86] method are depicted in Table 11. 
Table 11 Ranking of training aircraft according to AHP-TOPSIS method

\begin{tabular}{lcccc}
\hline & $d\left(p_{i j}, p_{j}^{+}\right)$ & $d\left(p_{i j}, p_{j}^{-}\right)$ & $C_{i}$ & Ranking \\
\hline Diamond 40 & 0.081 & 0.123 & 0.602 & 4 \\
Evektor & 0.088 & 0.117 & 0.571 & 5 \\
The tecnam & 0.070 & 0.124 & 0.639 & 2 \\
Pipera & 0.073 & 0.116 & 0.613 & 3 \\
Diamond 20 & 0.175 & 0.112 & 0.389 & 6 \\
Cessna 172 & 0.063 & 0.131 & 0.673 & 1 \\
\hline
\end{tabular}

Next, to illustrate the advantages of our proposed neutrosophic AHP-MULTIMOORA, a comparative analysis is conducted with AHP-TOPSIS [86] model. Fig.1 displays the ranking results of the six training aircraft for flight training organizations alternative as yielded using the mentioned methods. From Fig. 1, we can observe that given methods suggest Cessna 172 as the first choice for the considered training aircraft for flight training organizations. Moreover, the ranking orders of the six training aircraft for flight training determined by the proposed method are exactly matched with those derived by the neutrosophic AHP-TOPSIS method. This demonstrates the validity of the proposed decision-making framework. By comparison, the MULTIMOORA utilized in our proposed method is more comprehensive in dealing with training aircraft for flight training problems as it utilizes the ratio system, the reference point approach, and the full multiplicative form. Therefore, the reliability and veracity of the decision-making results would be improved greatly by using the proposed neutrosophic AHP-MULTIMOORA model.

Compared with the neutrosophic AHP-TOPSIS method in the literature, the AHPMULTIMOORA method developed in this study has the following attractions:

- The SVNSs improve the elicitation of linguistic information when a decisionmaker hesitates among several values to assess a training aircraft for flight training problems. The use of SVNSs provides a more flexible way to represent decisionmakers' evaluations. So, an organized method is given to combine expert knowledge and experience for use in selecting the optimal training aircraft for flight training organizations.

- The AHP method for importance coefficients of criteria is taken into account in the process of training aircraft for flight training evaluation and selection, which makes the proposed decision-making model more realistic, more practical, and more flexible.

- The MULTIMOORA method is used for the prioritization of training aircraft for flight training alternatives, which is a robust and powerful MCDM method and is easily implemented relative to other methods such as the TOPSIS and the VIKOR methods. Hence, the proposed method more effectively conducts robust evaluation for a particular manufacturing environment. 


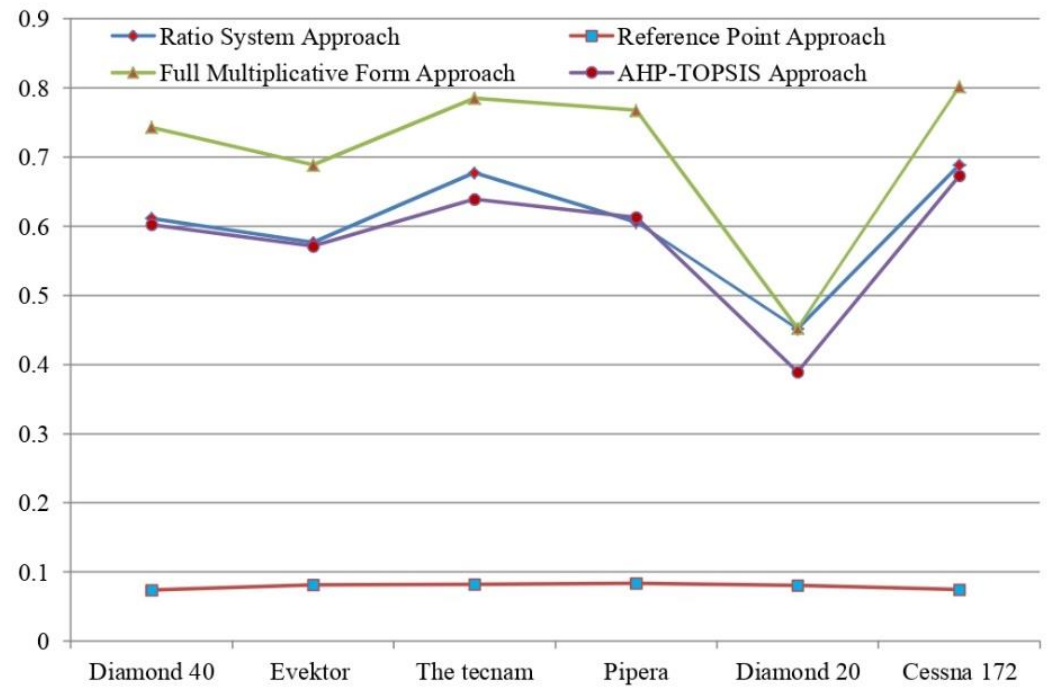

Fig. 1 Comparison of preference order of training aircraft derived by the different methods

\subsection{Sensitivity analysis}

The aim of the sensitivity analysis is to investigate the impact of various settings of criteria weights over different weight sets. In this paper, a sensitivity analysis was done to investigate the proposed approach behavior. Nine different criteria weight sets are taken and depicted in Table 12. In this table, for every set, one of the criteria has the maximum weight, while the other ones have lower weights. By applying this process, the ample scope of criteria weights was created to investigate the sensitivity of the developed approach to variation of the criteria weights.

Table 12 Different criteria weight sets for ranking of training aircraft

\begin{tabular}{|c|c|c|c|c|c|c|c|c|c|}
\hline & $\begin{array}{l}\text { Required } \\
\text { runway } \\
\text { length }\end{array}$ & $\begin{array}{c}\text { Capable } \\
\text { of } \\
\text { IFR/VFR } \\
\text { operations }\end{array}$ & $\begin{array}{c}\text { Reliability } \\
/ \\
\text { safety }\end{array}$ & $\begin{array}{l}\text { Purchasing } \\
\text { cost }\end{array}$ & $\begin{array}{l}\text { Maintenance } \\
\text { cost }\end{array}$ & $\begin{array}{l}\text { Operational } \\
\text { cost }\end{array}$ & $\begin{array}{l}\text { Certified } \\
\text { staff } \\
\text { number }\end{array}$ & $\begin{array}{l}\text { Availability } \\
\text { of facilities }\end{array}$ & $\begin{array}{l}\text { Ease of } \\
\text { finding } \\
\text { spare part }\end{array}$ \\
\hline Set-1 & 0.0926 & 0.1352 & 0.0889 & 0.0885 & 0.0935 & 0.1044 & 0.1345 & 0.1461 & 0.1159 \\
\hline Set-2 & 0.135 & 0.0889 & 0.0885 & 0.0935 & 0.1044 & 0.1345 & 0.1461 & 0.1159 & 0.0926 \\
\hline Set-3 & 0.0889 & 0.0885 & 0.0935 & 0.1044 & 0.1345 & 0.1461 & 0.1159 & 0.0926 & 0.1352 \\
\hline Set-4 & 0.0885 & 0.0935 & 0.1044 & 0.1345 & 0.1461 & 0.1159 & 0.0926 & 0.135 & 0.0889 \\
\hline Set-5 & 0.0935 & 0.1044 & 0.1345 & 0.1461 & 0.1159 & 0.0926 & 0.1352 & 0.0889 & 0.0885 \\
\hline Set- 6 & 0.1044 & 0.1345 & 0.1461 & 0.1159 & 0.0926 & 0.1352 & 0.0889 & 0.0885 & 0.0935 \\
\hline Set-7 & 0.1345 & 0.1461 & 0.1159 & 0.0926 & 0.1352 & 0.0889 & 0.0885 & 0.0935 & 0.1044 \\
\hline Set- 8 & 0.1461 & 0.1159 & 0.0926 & 0.1352 & 0.0889 & 0.0885 & 0.0935 & 0.1044 & 0.1345 \\
\hline Set-9 & 0.1159 & 0.0926 & 0.1352 & 0.0889 & 0.0885 & 0.0935 & 0.1044 & 0.1345 & 0.1461 \\
\hline
\end{tabular}


Table 13 Overall utility degree for each training aircraft with different values of weight sets

\begin{tabular}{ccccccc}
\hline Sets & Diamond 40 & Evektor & The tecnam & Pipera & Diamond 20 & Cessna 172 \\
\hline Set-1 & 0.7427 & 0.6865 & 0.7866 & 0.7661 & 0.4548 & 0.8019 \\
Set-2 & 0.7928 & 0.7133 & 0.8384 & 0.8032 & 0.5357 & 0.8629 \\
Set-3 & 0.8750 & 0.7785 & 0.9147 & 0.8818 & 0.6441 & 0.9294 \\
Set-4 & 0.8483 & 0.8006 & 0.8937 & 0.8907 & 0.6364 & 0.9375 \\
Set-5 & 0.8184 & 0.7102 & 0.8740 & 0.8403 & 0.5794 & 0.8900 \\
Set-6 & 0.8200 & 0.7113 & 0.8489 & 0.8146 & 0.5974 & 0.8701 \\
Set-7 & 0.7711 & 0.7186 & 0.8303 & 0.7973 & 0.5678 & 0.8403 \\
Set-8 & 0.7668 & 0.7165 & 0.8236 & 0.7773 & 0.5714 & 0.8370 \\
Set-9 & 0.7310 & 0.6474 & 0.7812 & 0.7578 & 0.4715 & 0.7899 \\
\hline
\end{tabular}

The sensitivity analysis results described in Table 13 and Fig. 2 show that the overall utility degree could change over different criteria weight sets and the rank of training aircraft alternative. For example, when decision experts (DEs) give the different criteria weight sets-1 to 9 , the ranking of training aircraft alternative is Cessna $172>$ The tecnam $>$ Diamond 40 $>$ Pipera $>$ Evektor $>$ Diamond 20. And Cessna 172 is the optimal alternative. We can observe that in each criterion weight set, Cessna 172 is the best option rank but the preference order of training aircraft alternative is also identical, which includes the experiments to manipulate factors and see how outcomes change, sensitivity analysis of a mathematical model reveals how outcomes respond to variate the criteria weight settings.

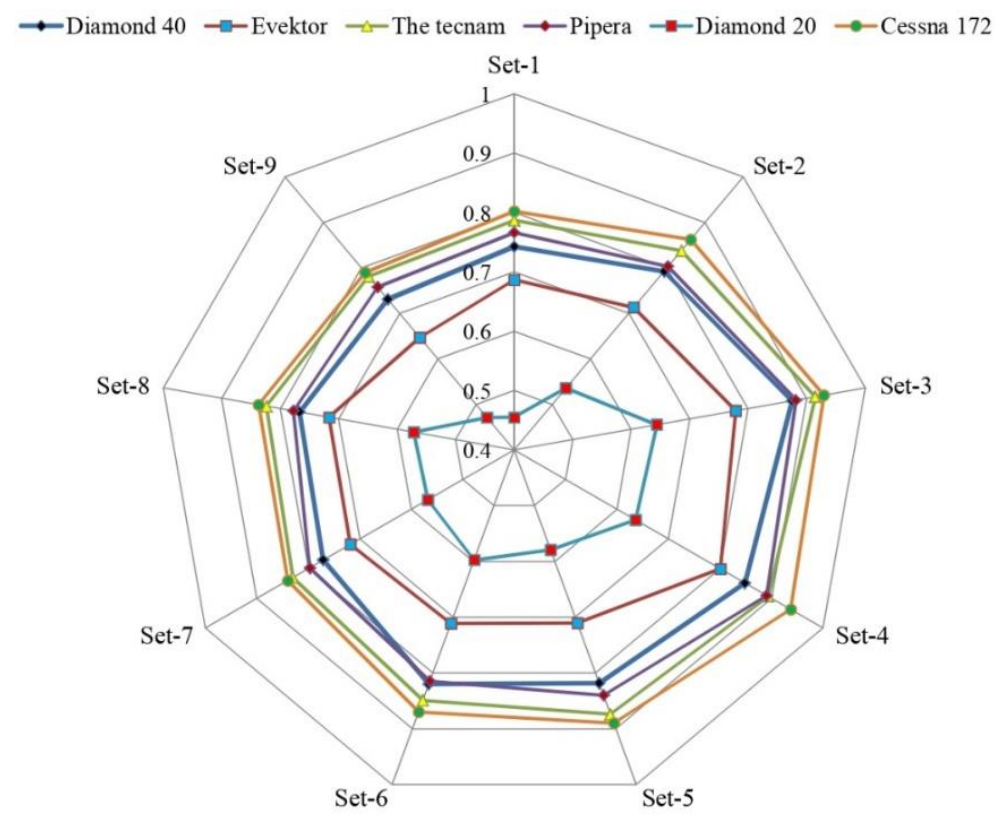

Fig. 2 Ranking of overall utility for each alternative with different values of weight sets

From the above discussion, it is concluded that the training aircraft alternative selection is dependent on and sensitive to these criteria weight sets. Therefore, the proposed approach has acceptable stability with different weight sets. 


\section{CONCLUSION}

In this study, training aircraft are ranked by using a neutrosophic AHP based neutrosophic Multimoora approach. For this aim firstly criteria for selecting the training aircraft are determined according to the depth literature review process and weighted via SVNS based AHP approach. Then the six training aircraft as alternatives are ranked by using SVNS based Multimoora method. SVNS are preferred compared to crisp, fuzzy, interval-valued, and intuitionistic sets due to efficiency, flexibility, and easiness for explaining decision-makers' indeterminate judgments. Furthermore, the selection of training aircraft as a complex realworld decision-making problem can be efficiently solved under neutrosophic sets based environment.

For further research studies criteria related to training aircraft selection can be expanded and results can be compared to different multi-criteria decision-making methods. A sensitivity analysis has also been performed with different criteria weights sets to represent the stability of the proposed approach. The analyses of the results show that the proposed approach has good efficiency and stability, and is well consistent with the other methods. Besides, alphaDiscounting method which was proposed by [59] can be used as an alternative to AHP for prioritizing criteria and obtaining consistent outputs with pairwise comparisons. It works for any number of preferences that can be transformed into a system of homogeneous (and/or non-homogeneous) linear (and/or non-linear) equations (and/or inequalities) and useful for avoiding the rank reversal produced by AHP. Also, various hybrid techniques can be proposed and applied to real-world complex decision-making problems.

\section{REFERENCES}

1. Dožić, S., Lutovac, T., Kalić, M., 2018, Fuzzy AHP approach to passenger aircraft type selection, Journal of Air Transport Management, 68, pp. 165-175.

2. Kenan, N., Jebali, A., Diabat, A., 2018, The integrated aircraft routing problem with optional flights and delay considerations, Transportation Research Part E: Logistics and Transportation Review, 118, pp. 355-375.

3. Liang, Z., Xiao, F., Qian, X., Zhou, L., Jin, X., Lu, X., Karichery, S., 2018, A column generation-based heuristic for aircraft recovery problem with airport capacity constraints and maintenance flexibility, Transportation Research Part B: Methodological, 113, pp. 70-90.

4. Maywald, J.D., Reiman, A.D., Overstreet, R.E., Johnson, A.W., 2019, Aircraft selection modeling: a multi-step heuristic to enumerate airlift alternatives, Annals of Operations Research, 274, pp. 425-445.

5. Zhang, J., Zhao, P., Zhang, Y., Dai, X., Sui, D., 2020, Criteria selection and multi-objective optimization of aircraft landing problem, Journal of Air Transport Management, 82, 101734.

6. Sánchez-Lozano, J.M., Rodríguez, O.N., 2020, Application of Fuzzy Reference Ideal Method (FRIM) to the military advanced training aircraft selection, Applied Soft Computing, 88, 106061

7. Wang, T.C., Chang, T.H., 2007, Application of TOPSIS in evaluating initial training aircraft under a fuzzy environment, Expert Systems with Applications, 33(4), pp. 870-880.

8. Dožić, S.,Kalić, M., 2014, An AHP approach to aircraft selection process, Transportation Research Procedia, 3, pp. 165-174.

9. Hunter, D.R., Burke, E.F., 1994, Predicting aircraft pilot-training success: A meta-analysis of published research, The International Journal of Aviation Psychology, 4(4), pp. 297-313.

10. Dožić, S., Kalić, M., 2015, Comparison of two MCDM methodologies in aircraft type selection problem, Transportation Research Procedia, 10, pp. 910-919.

11. Gomes, L.F.A.M., Mattos Fernandes, J.E., Mello, J.C.C.B.S., 2014, A fuzzy stochastic approach to the multicriteria selection of an aircraft for regional chartering, Journal of Advanced Transportation, 48(3), pp. 223-237.

12. Sun, X., Gollnick, V., Stumpf, E. 2011, Robustness Consideration in Multi-Criteria Decision Making to an Aircraft Selection Problem, Journal of Multi-Criteria Decision Analysis, 18(1-2), pp. 55-64.

13. Ilgin, M.A., 2019, Aircraft Selection Using Linear Physical Programming, Journal of Aeronautics and Space Technologies, 12(2), pp. 121-128. 
14. Yin, A., Gao, Z., Zhuanga, D., 2019, Discussion on Supplier Selection in the Selection of Large Civil Passenger Aircraft, Journal of Physics: Conference Series, 1187(5), 052007.

15. Smarandache, F., 1998, Neutrosophy:Neutrosophic Probability, Set, and Logic: Analytic Synthesis \& Synthetic Analysis, American Research Press.

16. See, T.K., Lewis, K., 2002, Multiattribute decision making using hypothetical equivalents, In ASME 2002 International Design Engineering Technical Conferences and Computers and Information in Engineering Conference, pp. 401-410.

17. Yeh, C.H., Chang, Y.H., 2009, Modeling subjective evaluation for fuzzy group multicriteria decision making, European Journal of Operational Research, 194(2), pp. 464-473.

18. Özdemir, Y., Başligil, H., Karaca, M., 2011, Aircraft selection using analytic network process: A case for Turkish airlines, Proceedings of the World Congress on Engineering, vol.2, pp.1155-1159.

19. Bruno, G., Esposito, E., Genovese, A., 2015, A model for aircraft evaluation to support strategic decisions, Expert Systems with Applications, 42(13), pp. 5580-5590

20. Kannan, D.,deSousa Jabbour, A.B.L.Jabbour, C.J.C., 2014, Selecting green suppliers based on GSCM practices: Using fuzzy TOPSIS applied to a Brazilian electronics company, European Journal of operational research, 233(2), pp. 432-447.

21. Lozano, J.M.S., Serna, J., Payan, A.D., 2015, Evaluating military training aircrafts through the combination of multi-criteria decision making processes with fuzzy logic. A case study in the Spanish Air Force Academy, Aerospace Science and Technology, 42, pp. 58-65.

22. Gürbüz, F., Göleç, A., Senyiğit, E., 2016, Determination of best military cargo aircraft with multi criteria decision making techniques, MANAS Sosyal Araştırmalar Dergisi, 5(5), pp. 87-101.

23. Özdemir, Y., Basligil, H., 2016, Aircraft selection using fuzzy ANP and the generalized choquet integral method: The Turkish airlines case, Journal of Intelligent \& Fuzzy Systems, 31(1), pp. 589-600.

24. Yurdusevimli, E., Özgen, A., 2017, Choosing the best training aircraft for a flight training organization by multi criteria decision making methods, The Online Journal of Science and Technology, 7(4), pp. 47-51.

25. Kirac1, K., Bakır, M., 2018, Application of commercial aircraft selection in aviation industry through multicriteria decision making methods, MCBU Sosyal Bilimler Dergisi, 16(4), pp. 307-332.

26. Durmaz, K.I.., Gencer, C., 2020, A new plugin based on JSMAA:SWARA-JSMAA and aerobatic aircraft selection, Journal of the Faculty of Engineering and Architecture of Gazi University, 35(3), pp. 1487-1498.

27. Kirac1, K., Akan, E., 2020, Aircraft selection by applying AHP and TOPSIS in interval type-2 fuzzy sets, Journal of Air Transport Management, 89, 101924

28. Ahmed, S.K., Sivakumar, G., Kabir, G., Ali, S.M., 2020, Regional aircraft selection integrating fuzzy analytic hierarchy process (FAHP) and efficacy method, Journal of Production Systems \& Manufacturing Science, 1(2), pp. 63-86.

29. Hoan, P.V., Ha, Y., 2021, ARAS-FUCOM approach for VPAF fighter aircraft selection, Decision Science Letters, 10(1), pp. 53-62.

30. Brauers, W.K.M., Zavadskas, E.K., 2010, Project management by multimoora as an instrument for transition economies, Technological and Economic Development of Economy, 16(1), pp. 5-24.

31. Brauers, W.K.M., Zavadskas, E.K., 2011, Multimoora Optimization Used to Decide on a Bank Loan to Buy Property, Technological and Economic Development of Economy, 17(1), pp. 174-188.

32. Balezentis, T., Zeng, S., 2013, Group multi-criteria decision making based upon interval-valued fuzzy numbers: An extension of the MULTIMOORA method, Expert System with Applications, 40(2), pp. 543-550.

33. Aksoy, E., Ömürbek, N., Karaatl, M., 2015, Use of AHP Based MULTIMOORA and COPRAS Methods for Evaluating the Performance of Turkish Coal Enterprises, Hacettepe University Journal of Economics and Administrative Sciences, 33(4), pp. 1-28.

34. Hafezalkotob, A., Hafezalkotob, A., Sayadi, M.K., 2016, Extension of MULTIMOORA Method with Interval Numbers: An Application in Materials Selection, Applied Mathematical Modelling, 40(2), pp.1372-1386.

35. Karabasevic, D., Stanujkic, D., Urosevic, S., Maksimovic, M., 2015, Selection of candidates in the mining industry based on the application of the SWARA and the MULTIMOORA methods, Acta Montanistica Slovaca, 20(2), pp. 116-124.

36. Zavadskas, E.K., Bausys, R., Juodagalviene, B., Sapranaviciene, I.G., 2017, Model for residential house element and material selection by neutrosophic MULTIMOORA method, Engineering Applications of Artificial Intelligence, 64, pp. 315-324.

37. Fattahi, R., Khalilzadeh, M., 2018, Risk evaluation using a novel hybrid method based on FMEA, extended MULTIMOORA, and AHP methods under fuzzy environment, Safety Science, 102, pp. 290-300.

38. Maghsoodi, A.I., Abouhamzeh, G., Khalilzadeh, M., Zavadskas, E.K., 2018, Ranking and selecting the best performance appraisal method using the MULTIMOORA approach integrated Shannon's entropy, Frontiers of Business Research in China, 12(2), pp. 1-21.

39. Wang, W., Liu, X., Qin, Y., 2018, A fuzzy Fine-Kinney-based risk evaluation approach with extended MULTIMOORA method based on Choquet integral, Computers \& Industrial Engineering, 125, pp. 111-123. 
40. Zarch, M.E., Moghaddam, R.T., Esfahanian, F., Sepehri, M.M., Azaron, A., 2018, Pharmacological therapy selection of type 2 diabetes based on the SWARA and modified MULTIMOORA methods under a fuzzy environment, Artificial Intelligence in Medicine, 87, pp. 20-33.

41. Liang, W., Zhao, G., Hong, C., 2019, Selecting the optimal mining method with extended multi-objective optimization by ratio analysis plus the full multiplicative form (MULTIMOORA) approach, Neural Computing and Applications, 31, pp. 5871-5886.

42. Dorfeshan, Y., Mousavi, S.M., Mohagheghi, V., Vahdani, B, 2018, Selecting project-critical path by a new interval type-2 fuzzy decision methodology based on MULTIMOORA, MOOSRA and TPOP methods, Computers \& Industrial Engineering, 120, pp. 160-178.

43. Liao, H., Qin, R., Gao, C., Wu, X., Hafezalkotob, A., Herrera, F., 2019, Score-HeDLiSF: A score function of hesitant fuzzy linguistic term set based on hesitant degrees and linguistic scale functions: An application to unbalanced hesitant fuzzy linguistic MULTIMOORA, Information Fusion, 48, pp. 39-54.

44. Gündoğdu, F. K., 2020, A spherical fuzzy extension of MULTIMOORA method, Journal of Intelligent \& Fuzzy Systems, 38(1), pp. 963-978

45. Lin, M., Huang, C., Xu, Z. 2020, MULTIMOORA based MCDM model for site selection of car sharing station under picture fuzzy environment, Sustainable Cities and Society, 53, 101873.

46. Asante, D., He, Z., Adjei, N.O., Asante, B., 2020, Exploring the barriers to renewable energy adoption utilising MULTIMOORA- EDAS method, Energy Policy, 142, 111479.

47. Rahimi, S., Hafezalkotob, A., Monavari, S.M., Hafezalkotob, A., Rahimi, R., 2020, Sustainable landfill site selection for municipal solid waste based on a hybrid decision-making approach: Fuzzy group BWMMULTIMOORA-GIS, Journal of Cleaner Production, 248, 119186.

48. Tavana, M., Shaabani, A., Mohammadabadi, S.M., Varzgani, N., 2021, An integrated fuzzy AHP- fuzzy MULTIMOORA model for supply chain risk-benefit assessment and supplier selection, International Journal of Systems Science: Operations \& Logistics, 8(3), pp. 238-261

49. Wu, S.M., You, X.Y., Liu, H.C., Wang, L.E., 2020, Improving quality function deployment analysis with the cloud MULTIMOORA method, International Transactions in Operational Research, 27(3), pp. 1600-1621.

50. Tanrıverdi, G., Lezki, Ş., 2021, Istanbul Airport (IGA) and quest of best competitive strategy for air cargo carriers in new competition environment: A fuzzy multi-criteria approach, Journal of Air Transport Management, 95, 102088.

51. Zadeh, L.A., 1965, Fuzzy sets, Information and control, 8(3), pp. 338-353.

52. Zadeh, L.A., 1975, The concept of a linguistic variable and its application to approximate reasoning-I, Information Sciences, 8(3), pp. 199-249.

53. Atanassov, K., 1986, Intuitionistic fuzzy sets, Fuzzy Sets and Systems, 20(1), pp. 87-96

54. Yager, R.R., 2014, Pythagorean membership grades in multicriteria decision making, IEEE Transactions on Fuzzy Systems, 22(4), pp. 958-965.

55. Yager, R.R., 2017, Generalized orthopair fuzzy sets, IEEE Transactions on Fuzzy Systems, 25(5), pp. $1222-1230$

56. Si, A., Das, S., Kar, S., 2019, An approach to rank picture fuzzy numbers for decision making problems, Decision Making: Applications in Management and Engineering, 2(2), pp. 54-64.

57. Mishra, A.R., Rani, P., Pardasani, K.R., Mardani, A., Stević, Z., Pamučar, D., 2020, A novel entropy and divergence measures with multi-criteria service quality assessment using interval valued intuitionistic fuzzy TODIM method, Soft Computing, 24, pp. 11641-11661.

58. Mishra, A.R., Sisodia, G., Raj Pardasani, K., Sharma, K., 2020, Multi-criteria IT personnel selection on intuitionistic fuzzy information measures and ARAS methodology, IranianJournal of Fuzzy Systems, 17(4), pp. $55-68$.

59. Smarandache, F., 2015, $\alpha$-Discounting Method for Multi-Criteria Decision Making ( $\alpha-D$ MCDM), SCS AdSumus, Oradea, Romania \& Educational Publisher, Columbus, USA.

60. Pramanik, S., Biswas, P., Giri, B. C., 2017, Hybrid vector similarity measures and their applications to multiattribute decision making under neutrosophic environment, Neural Computing and Applications, 28, pp. $1163-1176$

61. Liu, D., Liu, G., Liu, Z., 2018, Some Similarity Measures of Neutrosophic Sets Based on the Euclidean Distance and Their Application in Medical Diagnosis, Computational and Mathematical Methods in Medicine, 7325938.

62. Liu, F., Aiwu, G., Lukovac, V., Vukić, M., 2018, A multicriteria model for the selection of the transport service provider: a single valued neutrosophic DEMATEL multicriteria model, Decision Making: Applications in Management and Engineering, 1(2), pp. 121-130.

63. Wang, H., Smarandache, F., Zhang, Y.Q., Sunderraman, R., 2010, Single valued neutrosophic sets, Multispace and Multistructure, 4, pp. 410-413.

64. Pamučar, D., Božanić, D., 2019, Selection of a location for the development of multimodal logistics center: Application of single-valued neutrosophic MABAC model, Operational Research in Engineering Sciences: Theory and Applications, 2(2), pp. 55-71. 
65. Rani, P., Mishra, A.R., 2020, Single-valued neutrosophic SWARA-VIKOR framework for performance assessment of eco-industrial thermal power plants, ICSES Transactions on Neural and Fuzzy Computing, $3(1), 335$.

66. Sodenkamp, M.A., Tavana, M., Di Caprio, D., 2018, An aggregation method for solving group multi-criteria decision-making problems with single-valued neutrosophic sets, Applied Soft Computing, 71, pp. 715-727.

67. Thao, N.X., Smarandache, F., 2018, Divergence Measure of Neutrosophic Sets and Applications, Neutrosophic Sets and Systems, 21, pp. 142-152.

68. Qin, K., Wang, L., 2020, New similarity and entropy measures of single-valued neutrosophic sets with applications in multi-attribute decision making, Soft Computing, 24, pp. 16165-16176.

69. Tian, C., Peng, J.J., Zhang, Z.Q., Goh, M., Wang, J.Q., 2020, A Multi-Criteria Decision-Making Method Based on Single-Valued Neutrosophic Partitioned Heronian Mean Operator, Mathematics, 8(7), 1189.

70. Biswas, P., Pramanik, S., Giri, B.C., 2016, TOPSIS method for multi-attribute group decision making under single-valued neutrosophic environment, Neural Computing and Applications, 27, pp. 727-737.

71. Mondal, K., Pramanik, S., Smarandache, F., 2016, Several Trigonometric Hamming Similarity Measures of Rough Neutrosophic Sets and their Applications in Decision Making, In New Trends in Neutrosophic Theory and Applications, F. Smarandache and S. Pramanik (Ed.), Pons Publishing House, Brussels, pp. 93-103.

72. Biswas, P., Pramanik, S., Giri, B.C., 2016, Some Distance Measures of Single Valued Neutrosophic Hesitant Fuzzy Sets and Their Applications to Multiple Attribute Decision Making, In New Trends in Neutrosophic Theory and Applications, F. Smarandache and S. Pramanik (Ed.), Pons Publishing House, Brussels, pp. 27-34.

73. Abdel-Basset, M., Mohamed, M., Zhou, Y., Hezam, I., 2017, Multi-criteria group decision making based on neutrosophic analytic hierarchy process, Journal of Intelligent \& Fuzzy Systems, 33(6), pp. 4055-4066.

74. Abdel-Basset, M., Mohamed, M., Smarandache, F., 2018, An extension of neutrosophic AHP-SWOT analysis for strategic planning and decision making, Symmetry, 10(4), 116.

75. Stanujkic, D., Zavadskas, E.K., Smarandache, F., Brauers, W.K.M., Karabasevic, D., 2017, A Neutrosophic Extension of the Multimoora Method, Informatica, 28(1), pp. 181-192.

76. Şahin, R., 2014, Multi-criteria neutrosophic decision making method based on score and accuracy functions under neutrosophic environment, arXiv:1412.5202.

77. Balezentis, A., Balezentis, T., 2011, An innovative multi criteria supplier selection based on two tuple MULTIMOORA and hybrid data,Economic Computation and Economic Cybernetics Studies and Research, 45, pp. 37-56

78. Zavadskas, E.K., Antucheviciene, J., Saparauskas, J., Turskis, Z., 2013, MCDM methods WASPAS and MULTIMOORA: verification of robustness of methods when assessing alternative solutions, Economic Computation and Economic Cybernetics Studies and Research, 47(2), pp. 5-20.

79. Zeng, S., Balezentis, A., Su, W., 2013, The multi criteria hesitant fuzzy group decision making with MULTIMOORA method, Economic Computation and Economic Cybernetics Studies and Research, 47(3), pp. $171-184$

80. Liu, H.C., You, J.X., Lu, C., Chen, Y.Z., 2015, Evaluating healthcare waste treatment technologies using a hybrid multi criteria decision making model, Renewable and Sustainable Energy Reviews, 41, pp. 932-942.

81. Liu,H.C.,Fan, X.J., Li, P., Chen, Y.Z., 2014, Evaluating the risk of failure modes with extended MULTIMOORA method under fuzzy environment, Engineering Applications of Artificial Intelligence, 34, pp. 168-177.

82. Hafezalkotob, A., Hafezalkotob, A., 2017, Interval MULTIMOORA method with target values of attributes based on interval distance and preference degree:biomaterials selection, Journal of Industrial Engineering International, 13, pp. 181-198.

83. Zhao, H., You, J.X., Liu, H.C., 2017,Failure mode and effect analysis using MULTIMOORA method with continuous weighted entropy under interval-valued intuitionistic fuzzy environment, Soft Computing, 21, pp. 5355-5367.

84. Dai, W., Zhong, Q., Qi, C., 2020, Multi-stage multi-attribute decision-making method based on the prospect theory and triangular fuzzy MULTIMOORA, Soft Computing, 24, pp. 9429-9440.

85. Wensveen, J.G., 2011,Air transportation: a management perspective, 7th ed. Aldershot, England: Ashgate Publishing Ltd.

86. Ortega, R.G.,Vázquez, M.L., Figueiredo, J.A.S., Rodríguez, A.G., 2018, Sinos River basin Social-environmental prospective assessment of water quality management using fuzzy cognitive maps and neutrosophic AHPTOPSIS, Neutrosophic Sets and Systems, 23, pp. 160-171.

87. Ye, J., 2014, Single-Valued Neutrosophic Minimum Spanning Tree and Its Clustering Method, Journal of Intelligent Systems, 23(3), pp. 311-324. 
578 Ç. KARAMAŞA, D. KARABASEVIC, D. STANUJKIC, A.R. KOOKHDAN, A. R. MISHRA, ET AL.

\section{APPENDICES}

Appendix 1 Neutrosophic evaluation matrix for criteria

\begin{tabular}{|c|c|c|c|c|c|c|c|c|c|}
\hline Criteria & $\mathrm{C}_{1}$ & $\mathrm{C}_{2}$ & $\mathrm{C}_{3}$ & $\mathrm{C}_{4}$ & $\mathrm{C}_{5}$ & $\mathrm{C}_{6}$ & $\mathrm{C}_{7}$ & $\mathrm{C}_{8}$ & $\mathrm{C}_{9}$ \\
\hline $\mathrm{C}_{1}$ & $\left\langle\begin{array}{c}(1,1,1) ; \\
0.5,0.5,0.5\end{array}\right\rangle$ & $\begin{array}{c}(2,3,4) \\
\langle 0.3,0.75,\rangle \\
0.7\end{array}$ & $\begin{array}{c}(4,5,6) ; \\
\langle 0.8,0.15,\rangle \\
0.2\end{array}$ & $\begin{array}{c}(2,3,4) ; \\
\langle 0.3,0.75,\rangle \\
0.7\end{array}$ & $\begin{array}{c}(2,3,4) ; \\
\langle 0.3,0.75,\rangle \\
0.7\end{array}$ & $\begin{array}{c}(6,7,8) \\
\langle 0.9,0.1,\rangle \\
0.1\end{array}$ & $\left\langle\begin{array}{c}(1,1,1) ; \\
0.5,0.5,0.5\end{array}\right\rangle$ & $\begin{array}{c}(4,5,6) ; \\
\langle 0.8,0.15,\rangle \\
0.2\end{array}$ & $\begin{array}{c}(1,2,3) \\
\left\langle\begin{array}{c}0.4, \\
0.65 \\
0.6\end{array}\right\rangle\end{array}$ \\
\hline $\mathrm{C}_{2}$ & $\begin{array}{c}\left\langle\frac{1}{4}, \frac{1}{3}, \frac{1}{2}\right) ; \\
0.3,0.75 \\
0.7\end{array}$ & $\left\langle\begin{array}{c}(1,1,1) ; \\
0.5,0.5,0.5\end{array}\right\rangle$ & $\left\langle\begin{array}{c}(9,9,9) ; \\
1,0,0\end{array}\right\rangle$ & $\left\langle\begin{array}{c}(6,7,8) ; \\
0.9,0.1,0.1\end{array}\right\rangle$ & $\left\langle\begin{array}{c}(6,7,8) ; \\
0.9,0.1,0.1\end{array}\right\rangle$ & $\left\langle\begin{array}{c}(6,7,8) ; \\
0.9,0.1,0.1\end{array}\right\rangle$ & $\left\langle\begin{array}{c}(6,7,8) ; \\
0.9,0.1,0.1\end{array}\right\rangle$ & $\left\langle\begin{array}{c}(1,1,1) ; \\
0.5,0.5,0.5\end{array}\right\rangle$ & $\begin{array}{c}(6,7,8) ; \\
\langle 0.9,0.1,\rangle \\
0.1\end{array}$ \\
\hline $\mathrm{C}_{3}$ & $\begin{array}{c}\left\langle\left(\frac{1}{6}, \frac{1}{5}, \frac{1}{4}\right) ;\right. \\
0.8,0.15 \\
0.2\end{array}$ & $\begin{array}{c}\left\langle\left(\frac{1}{9}, \frac{1}{9}, \frac{1}{9}\right) ;\right\rangle \\
1,0,0\end{array}$ & $\left\langle\begin{array}{c}(1,1,1) ; \\
0.5,0.5,0.5\end{array}\right\rangle$ & $\left\langle\begin{array}{c}(6,7,8) ; \\
0.9,0.1,0.1\end{array}\right\rangle$ & $\begin{array}{c}(2,3,4) \\
\langle 0.3,0.75,\rangle \\
0.7\end{array}$ & $\left\langle\begin{array}{c}(1,1,1) ; \\
0.5,0.5,0.5\end{array}\right\rangle$ & $\left\langle\begin{array}{c}(1,1,1) ; \\
0.5,0.5,0.5\end{array}\right\rangle$ & $\begin{array}{c}(1,2,3) ; \\
\langle 0.4,0.65,\rangle \\
0.6\end{array}$ & $\left\langle\begin{array}{c}(9,9,9) ; \\
1,0,0\end{array}\right\rangle$ \\
\hline $\mathrm{C}_{4}$ & $\begin{array}{c}\left\langle\left(\frac{1}{4}, \frac{1}{3}, \frac{1}{2}\right) ;\right. \\
0.3,0.75 \\
0.7\end{array}$ & $\begin{array}{c}\left\langle\left(\frac{1}{8}, \frac{1}{7}, \frac{1}{6}\right) ;\right\rangle \\
0.9,0.1,0.1\end{array}$ & $\begin{array}{c}\left\langle\left(\frac{1}{8}, \frac{1}{7}, \frac{1}{6}\right) ;\right\rangle \\
0.9,0.1,0.1\end{array}$ & $\left\langle\begin{array}{c}(1,1,1) ; \\
0.5,0.5,0.5\end{array}\right\rangle$ & $\begin{array}{c}(4,5,6) ; \\
\langle 0.8,0.15,\rangle \\
0.2\end{array}$ & $\begin{array}{c}(4,5,6) ; \\
\langle 0.8,0.15,\rangle \\
\quad 0.2\end{array}$ & $\left\langle\begin{array}{c}(1,1,1) ; \\
0.5,0.5,0.5\end{array}\right\rangle$ & $\begin{array}{c}(2,3,4) ; \\
\langle 0.3,0.75,\rangle \\
0.7\end{array}$ & $\left.\begin{array}{c}(2,3,4) ; \\
0.3, \\
0.75,0.7\end{array}\right\rangle$ \\
\hline $\mathrm{C}_{5}$ & $\left.\begin{array}{c}\left\langle\left(\frac{1}{4}, \frac{1}{3}, \frac{1}{2}\right) ;\right. \\
0.3,0.75\end{array}\right\rangle$ & $\begin{array}{c}\left\langle\left(\frac{1}{8}, \frac{1}{7}, \frac{1}{6}\right) ;\right\rangle \\
0.9,0.1,0.1\end{array}$ & $\begin{array}{c}\left\langle\left(\frac{1}{4}, \frac{1}{3}, \frac{1}{2}\right) ;\right\rangle \\
0.3,0.75,0.7\end{array}$ & $\begin{array}{c}\left\langle\left(\frac{1}{6}, \frac{1}{5}, \frac{1}{4}\right) ;\right. \\
0.8,0.15\end{array}$ & $\left\langle\begin{array}{c}(1,1,1) ; \\
0.5,0.5,0.5\end{array}\right\rangle$ & $\left\langle\begin{array}{c}(6,7,8) ; \\
0.9,0.1,0.1\end{array}\right\rangle$ & $\left\langle\begin{array}{c}(1,1,1) ; \\
0.5,0.5,0.5\end{array}\right\rangle$ & $\left\langle\begin{array}{c}(6,7,8) ; \\
0.9,0.1,0.1\end{array}\right\rangle$ & $\left.\begin{array}{c}(4,5,6) \\
\left\langle\begin{array}{c}0.8, \\
0.15\end{array}\right. \\
0.2\end{array}\right\rangle$ \\
\hline $\mathrm{C}_{6}$ & $\begin{array}{c}\left\langle\left(\frac{1}{8}, \frac{1}{7}, \frac{1}{6}\right) ;\right\rangle \\
0.9,0.1,0.1\end{array}$ & $\begin{array}{c}\left\langle\left(\frac{1}{8}, \frac{1}{7}, \frac{1}{6}\right) ;\right\rangle \\
0.9,0.1,0.1\end{array}$ & $\left\langle\begin{array}{c}(1,1,1) ; \\
0.5,0.5,0.5\end{array}\right\rangle$ & $\begin{array}{c}\left\langle\left(\frac{1}{6}, \frac{1}{5}, \frac{1}{4}\right) ;\right\rangle \\
0.8,0.15,0.2\end{array}$ & $\begin{array}{c}\left\langle\left(\frac{1}{8}, \frac{1}{7}, \frac{1}{6}\right) ;\right\rangle \\
0.9,0.1,0.1\end{array}$ & $\left\langle\begin{array}{c}(1,1,1) ; \\
0.5,0.5,0.5\end{array}\right\rangle$ & $\begin{array}{c}(5,6,7) ; \\
\langle 0.7,0.25,\rangle \\
0.3\end{array}$ & $\begin{array}{c}(4,5,6) ; \\
\langle 0.8,0.15,\rangle \\
0.2\end{array}$ & $\left.\begin{array}{c}(5,6,7) \\
\left\langle\begin{array}{c}0.7 \\
0.25\end{array}\right. \\
0.3\end{array}\right\rangle$ \\
\hline $\mathrm{C}_{7}$ & $\left\langle\begin{array}{c}(1,1,1) ; \\
0.5,0.5,0.5\end{array}\right\rangle$ & $\begin{array}{c}\left\langle\left(\frac{1}{8}, \frac{1}{7}, \frac{1}{6}\right) ;\right\rangle \\
0.9,0.1,0.1\end{array}$ & $\left\langle\begin{array}{c}(1,1,1) ; \\
0.5,0.5,0.5\end{array}\right\rangle$ & $\left\langle\begin{array}{c}(1,1,1) ; \\
0.5,0.5,0.5\end{array}\right\rangle$ & $\left\langle\begin{array}{c}(1,1,1) ; \\
0.5,0.5,0.5\end{array}\right\rangle$ & $\begin{array}{c}\left\langle\left(\frac{1}{7}, \frac{1}{6}, \frac{1}{5}\right) ;\right. \\
0.7,0.25 \\
0.3\end{array}$ & $\left\langle\begin{array}{c}(1,1,1) ; \\
0.5,0.5,0.5\end{array}\right\rangle$ & $\begin{array}{c}(4,5,6) ; \\
\langle 0.8,0.15,\rangle \\
0.2\end{array}$ & $\begin{array}{c}(6,7,8) ; \\
\langle 0.9,0.1,\rangle \\
0.1\end{array}$ \\
\hline $\mathrm{C}_{8}$ & $\left.\begin{array}{c}\left\langle\frac{1}{6}, \frac{1}{5}, \frac{1}{4}\right) ; \\
0.8,0.15\end{array}\right\rangle$ & $\left\langle\begin{array}{c}(1,1,1) ; \\
0.5,0.5,0.5\end{array}\right\rangle$ & $\begin{array}{c}\left\langle\left(\frac{1}{3}, \frac{1}{2}, 1\right) ;\right. \\
0.4,0.65, \\
0.6\end{array}$ & $\begin{array}{c}\left\langle\left(\frac{1}{4}, \frac{1}{3}, \frac{1}{2}\right) ;\right. \\
0.3,0.75, \\
0.7\end{array}$ & $\begin{array}{c}\left\langle\left(\frac{1}{8}, \frac{1}{7}, \frac{1}{6}\right) ;\right\rangle \\
0.9,0.1,0.1\end{array}$ & $\begin{array}{c}\left\langle\left(\frac{1}{6}, \frac{1}{5}, \frac{1}{4}\right) ;\right. \\
0.8,0.15, \\
0.2\end{array}$ & $\begin{array}{c}\left\langle\left(\frac{1}{6}, \frac{1}{5}, \frac{1}{4}\right) ;\right. \\
0.8,0.15, \\
0.2\end{array}$ & $\left\langle\begin{array}{c}(1,1,1) ; \\
0.5,0.5,0.5\end{array}\right\rangle$ & $\left.\begin{array}{c}(4,5,6) \\
\left\langle\begin{array}{c}0.8, \\
0.15\end{array}\right. \\
0.2\end{array}\right\rangle$ \\
\hline $\mathrm{C}_{9}$ & $\begin{array}{c}\left\langle\left(\frac{1}{3}, \frac{1}{2}, 1\right) ;\right. \\
0.4,0.65, \\
0.6\end{array}$ & $\begin{array}{c}\left\langle\left(\frac{1}{8}, \frac{1}{7}, \frac{1}{6}\right) ;\right\rangle \\
0.9,0.1,0.1\end{array}$ & $\begin{array}{c}\left\langle\left(\frac{1}{9}, \frac{1}{9}, \frac{1}{9}\right) ;\right\rangle \\
1,0,0\end{array}$ & $\begin{array}{c}\left(\frac{1}{4}, \frac{1}{3}, \frac{1}{2}\right) ; \\
0.3,0.75, \\
0.7\end{array}$ & $\begin{array}{c}\left\langle\left(\frac{1}{6}, \frac{1}{5}, \frac{1}{4}\right) ;\right. \\
0.8,0.15, \\
0.2\end{array}$ & $\left.\begin{array}{c}\left\langle\left(\frac{1}{7}, \frac{1}{6}, \frac{1}{5}\right) ;\right. \\
0.7,0.25\end{array}\right\rangle$ & $\begin{array}{c}\left\langle\left(\frac{1}{8}, \frac{1}{7}, \frac{1}{6}\right) ;\right\rangle \\
0.9,0.1,0.1\end{array}$ & $\begin{array}{c}\left\langle\left(\frac{1}{6}, \frac{1}{5}, \frac{1}{4}\right) ;\right. \\
0.8,0.15, \\
0.2\end{array}$ & $\begin{array}{c}(1,1,1) ; \\
\langle 0.5,0.5,\rangle \\
0.5\end{array}$ \\
\hline
\end{tabular}

Appendix 2 Neutrosophic evaluation matrix for six training aircraft obtained from 10 decision makers

\begin{tabular}{|c|c|c|c|c|c|c|c|c|c|}
\hline & $\mathrm{C}_{1}$ & $\mathrm{C}_{2}$ & $\mathrm{C}_{3}$ & $\mathrm{C}_{4}$ & $\mathrm{C}_{5}$ & $\mathrm{C}_{6}$ & $\mathrm{C}_{7}$ & $\mathrm{C}_{8}$ & $\mathrm{C}_{9}$ \\
\hline Diamond 40 & $\left\langle\begin{array}{c}0.68,0.3, \\
0.32\end{array}\right\rangle$ & $\left.\begin{array}{c}0.75,0.22 \\
, 0.25\end{array}\right\rangle$ & $\left\langle\begin{array}{c}0.77,0.21, \\
0.23\end{array}\right\rangle$ & $\left\langle\begin{array}{c}0.79,0.2, \\
0.21\end{array}\right\rangle$ & $\left\langle\begin{array}{c}0.79,0.19 \\
0.21\end{array}\right\rangle$ & $\left\langle\begin{array}{c}0.65,0.34, \\
0.35\end{array}\right\rangle$ & $\begin{array}{c}0.78 \\
\langle 0.21,\rangle \\
0.22\end{array}$ & $\left\langle\begin{array}{c}0.64,0.36 \\
0.36\end{array}\right\rangle$ & $\begin{array}{c}0.84, \\
\langle 0.15,\rangle \\
0.16\end{array}$ \\
\hline Evektor & $\left\langle\begin{array}{c}0.75,0.24 \\
0.25\end{array}\right\rangle$ & $\left\langle\begin{array}{c}0.82,0.17 \\
0.18\end{array}\right\rangle$ & $\left\langle\begin{array}{c}0.54,0.47 \\
0.46\end{array}\right\rangle$ & $\left\langle\begin{array}{c}0.77,0.21 \\
0.23\end{array}\right\rangle$ & $\left\langle\begin{array}{c}0.67,0.29 \\
0.33\end{array}\right\rangle$ & $\left\langle\begin{array}{c}0.78,0.2, \\
0.22\end{array}\right\rangle$ & $\left\langle\begin{array}{c}0.6,0.38, \\
0.4\end{array}\right\rangle$ & $\left\langle\begin{array}{c}0.8,0.19 \\
0.2\end{array}\right\rangle$ & $\begin{array}{c}0.76, \\
\langle 0.22,\rangle \\
0.24\end{array}$ \\
\hline The tecnam & $\left\langle\begin{array}{c}0.74,0.21 \\
0.26\end{array}\right\rangle$ & $\left\langle\begin{array}{c}0.76,0.23 \\
0.24\end{array}\right\rangle$ & $\left\langle\begin{array}{c}0.78,0.2, \\
0.22\end{array}\right\rangle$ & $\left\langle\begin{array}{c}0.77,0.21 \\
0.23\end{array}\right\rangle$ & $\left\langle\begin{array}{c}0.7,0.28 \\
0.3\end{array}\right\rangle$ & $\left\langle\begin{array}{c}0.78,0.19 \\
0.22\end{array}\right\rangle$ & $\left\langle\begin{array}{c}0.85,0.14 \\
0.15\end{array}\right\rangle$ & $\left\langle\begin{array}{c}0.63,0.35 \\
0.37\end{array}\right\rangle$ & $\left\langle\begin{array}{c}0.89,0.1, \\
0.11\end{array}\right\rangle$ \\
\hline Pipera & $\left\langle\begin{array}{c}0.66,0.3, \\
0.34\end{array}\right\rangle$ & $\left\langle\begin{array}{c}0.7,0.25 \\
0.3\end{array}\right\rangle$ & $\left\langle\begin{array}{c}0.8,0.18 \\
0.2\end{array}\right\rangle$ & $\left\langle\begin{array}{c}0.81,0.17 \\
0.19\end{array}\right\rangle$ & $\langle 0.64,0.34,0$. . & $\left\langle\begin{array}{c}0.8,0.17 \\
0.2\end{array}\right\rangle$ & $\left\langle\begin{array}{c}0.77,0.2 \\
0.23\end{array}\right\rangle$ & $\left\langle\begin{array}{c}0.75,0.22, \\
0.25\end{array}\right\rangle$ & $\left\langle\begin{array}{c}0.81,0.17 \\
0.19\end{array}\right\rangle$ \\
\hline Diamond 20 & $\left\langle\begin{array}{c}0.75,0.21, \\
0.25\end{array}\right\rangle$ & $\left\langle\begin{array}{c}0.62,0.33, \\
0.38\end{array}\right\rangle$ & $\left\langle\begin{array}{c}0.59,0.38, \\
0.41\end{array}\right\rangle$ & $\left\langle\begin{array}{c}0.59,0.38 \\
0.41\end{array}\right\rangle$ & $\left\langle\begin{array}{c}0.66,0.29, \\
0.34\end{array}\right\rangle$ & $\left\langle\begin{array}{c}0.64,0.31, \\
0.36\end{array}\right\rangle$ & $\left\langle\begin{array}{c}0.46,0.56 \\
0.54\end{array}\right\rangle$ & $\left\langle\begin{array}{c}0.45,0.57 \\
0.55\end{array}\right\rangle$ & $\left\langle\begin{array}{c}0.7,0.25 \\
0.3\end{array}\right\rangle$ \\
\hline Cessna 172 & $\left\langle\begin{array}{c}0.77,0.2, \\
0.23\end{array}\right\rangle$ & $\left\langle\begin{array}{c}0.73,0.25 \\
0.27\end{array}\right\rangle$ & $\left\langle\begin{array}{c}0.76,0.21, \\
0.24\end{array}\right\rangle$ & $\left\langle\begin{array}{c}0.7,0.26 \\
0.3\end{array}\right\rangle$ & $\left\langle\begin{array}{c}0.69,0.28, \\
0.31\end{array}\right\rangle$ & $\left\langle\begin{array}{c}0.71,0.26 \\
0.29\end{array}\right\rangle$ & $\left\langle\begin{array}{c}0.78,0.19 \\
0.22\end{array}\right\rangle$ & $\left\langle\begin{array}{c}0.72,0.24 \\
0.28\end{array}\right\rangle$ & $\left\langle\begin{array}{c}0.77,0.2, \\
0.23\end{array}\right\rangle$ \\
\hline
\end{tabular}

